Collaborative Urban Transportation: Recent Advances in Theory and Practice

Catherine Cleophas, Caitlin Cottrill, Jan Fabian Ehmke, Kevin Tierney

PII:

DOI:

Reference:

To appear in:

Received date:

Revised date:

Accepted date:
S0377-2217(18)30341-2

10.1016/j.ejor.2018.04.037

EOR 15099

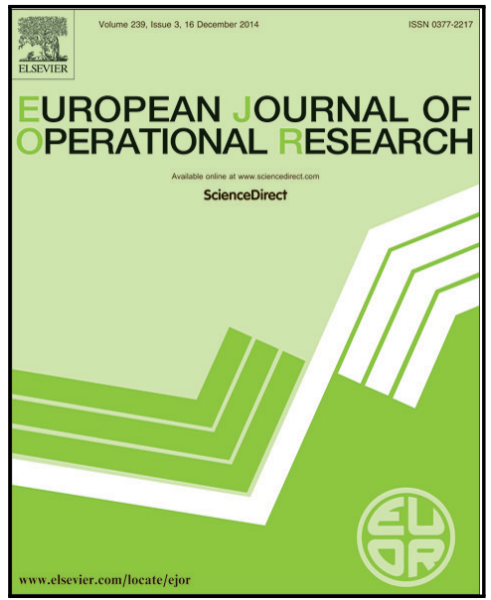

Please cite this article as: Catherine Cleophas, Caitlin Cottrill, Jan Fabian Ehmke, Kevin Tierney, Collaborative Urban Transportation: Recent Advances in Theory and Practice, European Journal of Operational Research (2018), doi: 10.1016/j.ejor.2018.04.037

This is a PDF file of an unedited manuscript that has been accepted for publication. As a service to our customers we are providing this early version of the manuscript. The manuscript will undergo copyediting, typesetting, and review of the resulting proof before it is published in its final form. Please note that during the production process errors may be discovered which could affect the content, and all legal disclaimers that apply to the journal pertain. 


\section{Highlights}

- Comprehensive overview of OR approaches for collaborative urban transportation

- Analyzes real-world collaborative transportation systems, assessing pros and cons

- Research outlook for the emerging field of collaborative transport optimization

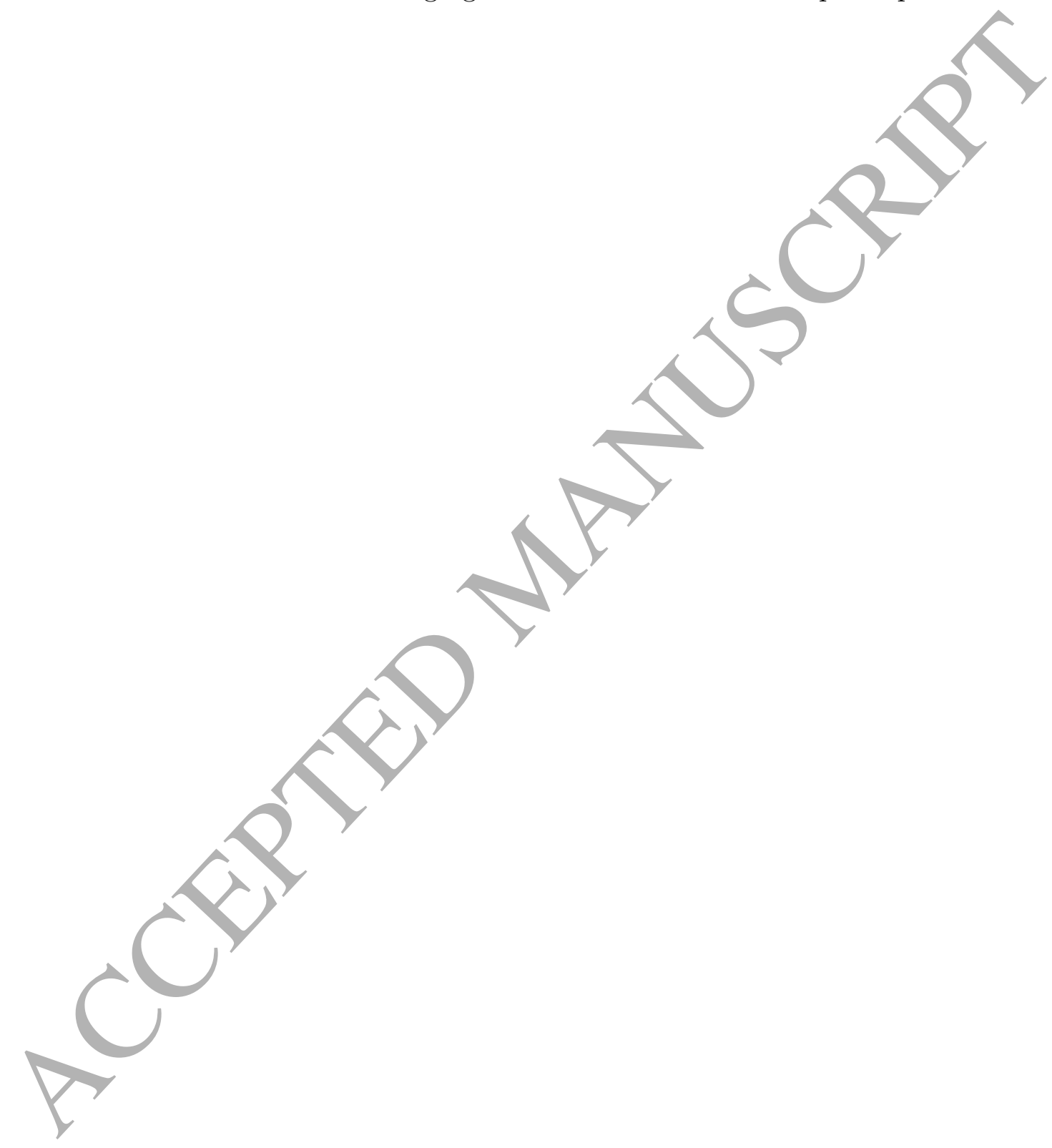




\title{
Collaborative Urban Transportation: Recent Advances in Theory and Practice
}

\author{
Catherine Cleophas $^{\mathrm{a}}$, Caitlin Cottrill ${ }^{\mathrm{b}}$, Jan Fabian Ehmke ${ }^{\mathrm{c}}$, Kevin Tierney ${ }^{\mathrm{d}}$ \\ ${ }^{a}$ Department Management Science, Lancaster University Management School \\ ${ }^{b}$ Centre for Transport Research, University of Aberdeen \\ ${ }^{c}$ Management Science Group, University of Magdeburg \\ ${ }^{d}$ Decision Support $\&$ Operations Research Lab, University of Paderborn
}

\begin{abstract}
Increasing urbanization has turned transporting freight from, to, and within urban areas into a major challenge. Freight transportation represents a lifeline for urban retail and industry, but causes significant negative impacts on the quality of living in urban areas in terms of congestion, emissions and space consumption. City logistics initiatives have long suggested the need for collaborative and environmentally friendly urban transportation that could alleviate the negative impacts of urban transportation, but these face organizational and technological challenges of collaboration. Given technological advancements and innovative business models, concepts of collaborative urban transportation could contribute to a future paradigm of more sustainable and customer-friendly urban transportation.

In this work, we collect and discuss contributions to collaborative freight transportation in urban areas with focus on recent publications (i.e. those published over the past ten years). We particularly analyze vertical and horizontal approaches of collaboration from an operations research perspective and point out strategic, tactical, and operational planning problems and solution approaches. To highlight research gaps and future research opportunities, we present innovative examples of collaborative urban transportation and analyze factors of failure and success. Collecting recent advances in theory and practice of collaborative urban transportation allows us to distill alternative visions of future collaborative freight transportation in urban areas.
\end{abstract}

Keywords: urban logistics, collaborative transportation, review, collaboration

\section{Introduction}

More than half of the global population currently lives in urban areas. The World Health Organization predicts that the population in urban areas will continue to expand by more than $1.5 \%$ per year until 2030 (WHO, 2010). The likely consequences of this are more traffic congestion, pollution, and noise, but also larger customer bases and business opportunities for economies of scale. Moving cargo between and within cities while preserving the residents' high quality of life is a key challenge for city planners and logistics service providers. 
Logistics and transportation enable economic development, but they are traditionally quite inefficient in urban areas. As shown in Rose et al. (2017), urban areas are characterized by the interplay of different stakeholder interest in close quarters, and, as highlighted in Kin et al. (2017), megacities add growing sustainability challenges. Further obstacles include low load factors, empty trips, long dwell times at loading and unloading points, and large numbers of deliveries to individual customers (Cepolina and Farina, 2015). The key challenge for the future is rethinking the way existing infrastructure is used and how new infrastructure is built, so that it is fully utilized and negative externalities are minimized.

One way forward is through collaboration between businesses, logistics service providers, citizens, and the public sector. By working together, multiple actors or stakeholders increase their efficiency through sharing resources, such as vehicles, cargo consolidation or distribution centers, or last mile delivery services. Collaboration could potentially lead to fewer vehicles in urban areas, less pollution, and lower prices for goods. However, experience from past logistics practice has shown that collaboration in city logistics projects is challenging, since additional efforts of planning and control of collaboration are significant. Due to technological advancements in recent years, new business models have emerged that focus on collaboration with customers to provide better logistics services. For instance, a variety of start-ups rely on the idea that customers deliver parcels to other customers (Rougès and Montreuil, 2014). Recipients can now decide to have their packages delivered to their trunk (Reyes et al., 2017), which requires logistics service providers and consumers to synchronize their planning.

There are two key types of collaborative transport: vertical and horizontal. For vertical collaboration, transport is often organized along modes and service operators. For instance, the first leg within the city may be carried out by conventional trucks, whereas the last mile to the recipient may be operated by environment-friendly city freighters or freight bikes. In horizontal collaboration, multiple providers work together in the same section of the transport chain, potentially sharing orders and infrastructure.

The operations research (OR) and the civil engineering communities have launched significant efforts to improve urban transportation. For the most part, urban transport utilizes standard trucks or light goods vehicles up to 3.5 tons, respectively. Browne et al. (2010) survey light-goods vehicles and analyze their rather negative impact on urban areas. Bektaş et al. (2017) provide an overview, describing efforts from different perspectives: system (infrastructure), planning problems, and business models. The authors also summarize optimization approaches that support planning and operation of urban transportation systems. They highlight that innovations such as standardized containers and combined passenger and freight transportation may improve future urban delivery. Savelsbergh and Van Woensel (2016) give the most recent overview from an OR perspective, discussing trends that include the increase of e-commerce, need for speed, sustainability, the sharing economy, population growth, and technological advancements. The authors also consider the multiechelon problem, which is at the core of synchronizing different tiers and modes for vertical collaboration in urban transportation systems.

This paper analyzes theoretical contributions published during the last ten years and aims to shed light on recent OR concepts of collaboration in urban freight transporta- 
tion. We identify relevant references via a search in Google Scholar, searching for a set of keywords including transport, freight, urban, horizontal collaboration, vertical collaboration, crowd shipping and ride sharing. We also consider relevant synonyms, substituting, for example, collaboration by cooperation. We expand the resulting pool of references by considering works that they cite or by which they are cited. We limit the scope to collaborative urban transport by analyzing the papers' titles and abstracts. We exclude conference papers if the authors expanded a similar contribution in a journal paper. We further exclude white papers and websites from the review of theoretical contributions, choosing to focus on peer-reviewed contributions. We do cite these sources if they describe relevant real-world projects. While we concentrate on the methodology of OR, papers from the domains of information systems and operations management are referenced when relevant. Furthermore, we consider references cited by or citing existing survey papers such as Bektaş et al. (2017) or Savelsbergh and Van Woensel (2016). We additionally provide references that date back more than ten years if these represent a crucial foundation for further research in the related area.

We list existing surveys that focus on research related to urban transport under the relevant subsections. In contrast to, e.g., surveys of real-world projects such as Cruijssen et al. (2007), the list of projects considered here is not limited to certain countries or collaboration types. In contrast to, e.g., reviews of literature on methodological subdomains such as the sharing of cost and benefits considered in Guajardo and Rönnqvist (2016), we aim for a holistic view of collaborative urban transport. Given existing reviews such as Agatz et al. (2012), we limit our review of crowd-shipping as well as of ride-sharing involving passengers and freight to the last five years. In the light of a recent thorough review of collaborative routing in general by Gansterer and Hartl/2017), we consider a wider scope of problem areas but concentrate on the domain of urban transport.

While focusing on freight transport, we also consider passenger transport when the collaborative aspect combines passengers and freight. For example, Li et al. (2014) present operational planning approaches for a business case where shared taxis transport both passengers and parcels. Such collaboration is already common in other logistics sectors, such as when aircraft or ferries earry both freight and passengers, but surface urban transportation provides few notable examples thus far.

Many OR contributions present solution approaches for planning and operating urban transportation systems; however, these approaches often oversimplify practice requirements and ignore challenges of synchronization between different players and modes. To demonstrate this, we also survey reports on trials of innovative urban transportation systems. Our survey aims to connect insights from real-world trials and the state of the art of modeling urban transportation mathematically. Furthermore, we offer an outlook on what technical aspects a system would need to contain to achieve success, and provide a set of challenges to the transportation and optimization communities.

In particular, Section 2 details the perspectives we use to analyze different collaboration approaches for urban transportation. Section 3 summarizes the idea of vertical collaboration via city logistics and multi-echelon networks, and highlights concepts of collaboration with customers. Horizontal collaboration is discussed in Section 4, focusing on challenges 
of sharing cost and benefits in the supply chain. Section 5 provides an overview of innovative real-world approaches for collaborative urban transportation. Section 6 identifies implications for future OR work, and the paper is concluded in Section 7.

\section{Dimensions of Collaborative Transportation}

This paper categorizes innovative forms of collaboration in urban logistics and transportation based on different categorical dimensions. In the following, we describe these dimensions and how we apply them to structure the subsequent sections.

First, we differentiate the direction of collaboration, following Pomponi et al. (2013), and consider vertical and horizontal coalitions. In vertical coalitions, partners serve distinct parts of the transportation network. This often means serving distinct tiers - e.g., long-haul versus last-mile, and hence requires synchronization between distinct tiers as proposed by and investigated in city logistics concepts, see Section 3. Vertical coalitions are often modeled and optimized by multi-echelon networks, synchronizing the flow of goods between the tiers, increasing efficiency and ensuring service quality. In vertical coalitions, collaboration may even go beyond partnering service providers. In another form of vertical cooperation between provider and customers, customers take over the final part of the delivery chain by picking up parcels from a packing station. We consider the resulting problems of synchronizing transport tiers, locating pick-up points, and incentivizing customers to use them in Section 3.

In horizontal coalitions, partners serve the same or at least overlapping parts of the transport network. An example is request sharing, where multiple providers accept requests and exchange them to improve the efficiency of pickups and deliveries. Horizontal collaboration within a single tier of the supply chain may not only necessitate deciding who transports what, but also what is transported when. In other words, goods and passengers may share the same mode, effectively collaborating as objects of transport. In urban transport, low load factors and a large number of deliveries to individual customers motivate horizontal collaboration to increase efficiency. We consider the resulting problems of ride-sharing as well as request, cost, and profit sharing in Section 4.

Combining vertical and horizontal coalitions to maximize transport efficiency is one of the major aspects of the Physical Internet (PI) movement. Relevant reviews of this burgeoning field, such as Sternberg and Norrman (2017), mostly take an engineering perspective. Our examination of vertical and horizontal collaboration methods examines the related planning problems from an OR perspective.

Planning decisions in collaborative transportation and logistics can consider different time horizons; here we differentiate strategic, tactical, and operational decisions. In this regard, we follow the text-book definition given, for instance, in Schmidt and Wilhelm (2000): Strategic planning impacts the firm's value-creation in the long-term, e.g. by defining the number and location of facilities or the number of vehicles available. We consider decisions regarding whether to enter a coalition and how to choose partners as strategic decisions. Tactical planning comprises mid-term policies to be implemented in the framework given by strategic decisions. This can include inventory levels or delivery frequencies. We consider policies to distribute cost and benefits among coalition partners as part of tactical planning. 
Operational planning aims to ensure timely and cost-efficient operations. As any decision that can be dynamically adjusted to fit the current conditions is part of operational planning, this can include delivery schedules, routes, and vehicle assignment. We particularly focus on request assignment and routing as operational decisions.

Collaborative planning can be conducted from a centralized or decentralized perspective. In one extreme, a central planner considers all available information to determine a binding decision for all collaboration partners. For example, in a two-echelon system, a central planner can use full information about inventories and order information to fix routes and delivery schedules on both tiers. In the other extreme, each coalition partner plans independently without exchanging information - clearly, the absolute extreme of decentralized planning dissolves the coalition. As either is unrealistic, we consider this dimension as fluid, so that any approach to collaborative transportation has to include the decision of how much and what type of information to exchange between partners and how to motivate partners to abide by the coalition decisions. Partners' decisions to stick to jointly optimal plans is governed by the impact of cost and benefit sharing and can be considered from a game theoretical perspective. We discuss this aspect with regard to horizontal collaboration in Section 4.2. Note that in practical implementations, not just the conditions of the planning model, but also technical, organizational, and legal restrictions determine the degree of information exchange.

For many planning problems in urban transportation, routing vehicles, passengers, and goods play an important role. Since this work does not primarily focus on the numerous variants of and approaches for routing, we limit our discussion to pointing out relevant related surveys as a starting point for the interested reader. Cattaruzza et al. (2015) survey the most relevant aspects of vehicle routing in city logistics. They classify different types of urban freight movement and highlight specific challenges of city logistics routing, e.g., time dependency due to congested road networks, multi-tier distribution, and the necessity of smaller, environment-friendly vehicles of limited range and capacity, operating multiple consecutive routes during a day (multi-trip vehicle routing). With regard to collaborative routing, Gansterer and Hartl (2017) provide a thorough literature review. In our paper, we focus on contributions that highlight particular aspects of the problem as relevant for urban transport.

Finally, we present a variety of real-world implemented systems that combine aspects of vertical and horizontal collaboration. Therefore, in Section 5, we investigate these systems and analyze how they work and try to determine what has made them a success or failure. We categorize systems based on the mode of transportation, although many of these systems use light rail, which almost by definition requires logistics service providers to employ multiple modes of transport to first feed goods into the light-rail network and later deliver goods on the last mile of the transport network.

\section{Vertical Collaboration}

In this section, we discuss examples of and approaches to vertical collaboration in urban transportation. Vertical collaboration describes the activities required when splitting up the 
supply chain into several tiers according to economic, environmental, legal, or organizational restrictions (Savelsbergh and Van Woensel, 2016). The concept of city logistics addresses the core aspects and challenges of vertical collaboration: What is the optimal number of tiers, how can the routes for the individual tiers be planned, and how can transport be synchronized between different tiers? Where should transshipment facilities be located, and is there enough physical space for transshipment (which may significantly impact the synchronization between tiers)? Finally, how can logistics service providers collaborate vertically with customers by providing opportunities and incentives for customers to pick up their deliveries? The approaches and references we consider are summarized in Table 1.

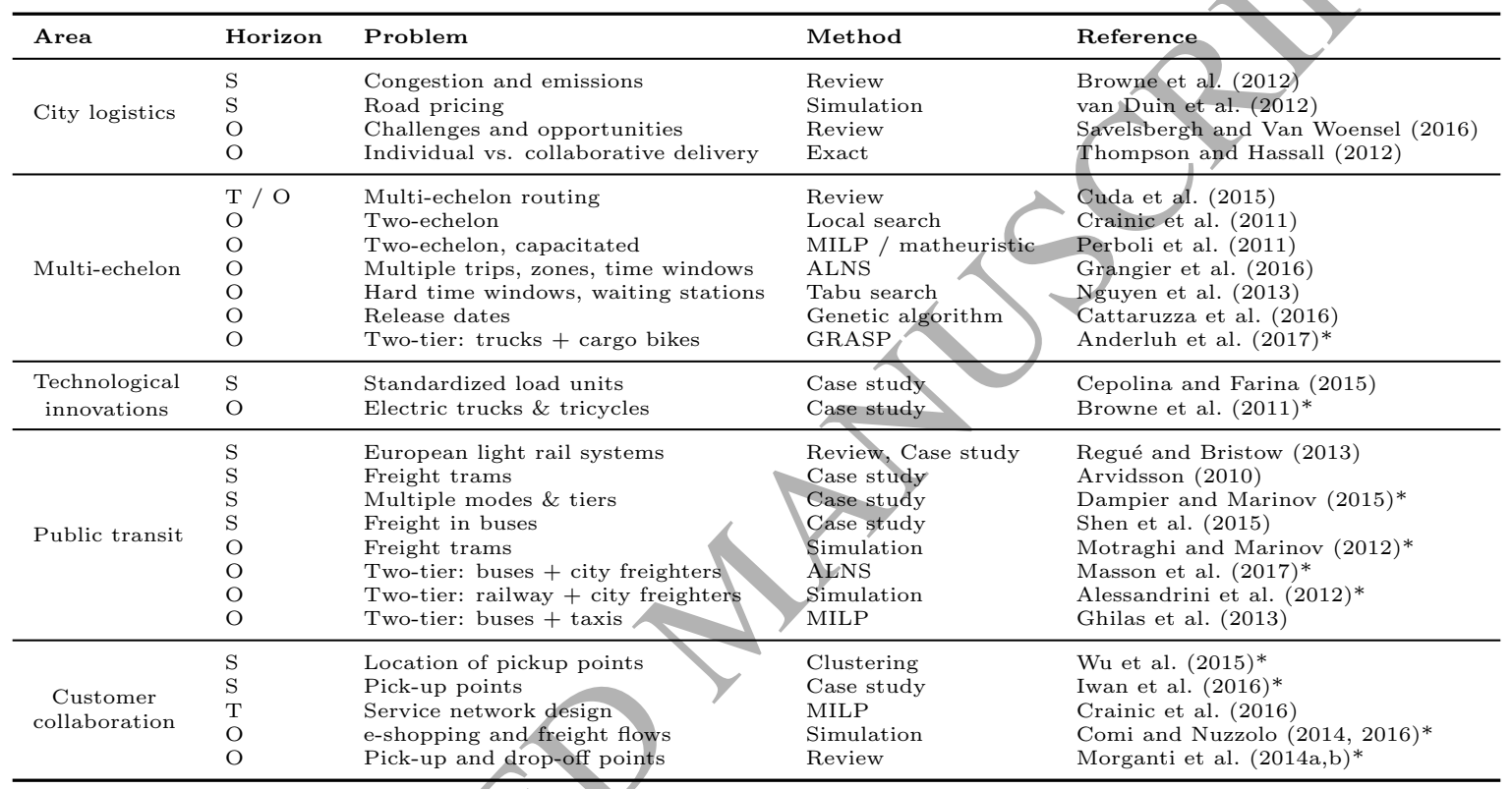

Table 1: An overview of the vertical collaboration literature ( $\mathrm{S}=$ strategic planning, $\mathrm{T}=$ tactical planning, $\mathrm{O}=$ operational planning; $*$ denotes the use of real-world data).

\subsection{Urban Consolidation Centers}

The idea of city logistics represents a well-known concept for collaboration, where longdistance transports are consolidated in Urban Consolidation Centers (UCCs). As UCCs are typically located at the city border, smaller, often environment-friendly vehicles take over the transport of goods on the last mile to the final recipient (Taniguchi and Van Der Heijden, 2000; Quak and de Koster, 2009; Cattaruzza et al., 2015). Given a sufficient number of deliveries, it can be reasonable for shippers to implement this concept by splitting their supply chains into multiple tiers. Since there is usually more than one shipper in an urban area, city logistics requires the collaboration of different shippers. In an ideal setting, shippers deliver their goods to the UCC and jointly organize last-mile deliveries, which helps to achieve a higher overall efficiency of the logistics system. City logistics becomes particularly challenging when several companies jointly operate a UCC, since the goods collected from multiple shippers need to be transshipped and consolidated for the transport 
within subsequent tiers of the supply chain. This requires significant efforts, especially for the synchronization of goods and for establishing transportation infrastructure between coalition partners. The joint operation of a UCC can be analyzed from both a vertical as well as a horizontal collaboration perspective, see also Section 4 for a review of horizontal collaboration aspects.

To highlight the challenges and value of collaboration in city logistics, some studies compare the cost of direct delivery strategies with multi-tier-based deliveries. Cost advantages are demonstrated by Thompson and Hassall (2012), who aim to reduce both the number of vehicles required and the total distance traveled with collaborative delivery. Since it is common in many retail sectors for a moderate number of suppliers or shippers to service a large number of the same retail stores in an urban area, cost savings can be achieved easily. Browne et al. (2012) investigate the role of UCCs with regard to urban congestion and emissions, highlighting challenges of vertical collaboration such as the functionality and ownership of the UCC and the underlying transportation network structure. Through multi-agent simulation, van Duin et al. (2012) investigate the impact of road pricing on the success of collaborative city logistics, highlighting that cost plays a critical role when firms decide whether to adopt consolidation. This is a crucial aspect when implementing UCCs in practice.

Many papers published in OR journals focus on the optimization of transportation between several tiers, which is usually framed and modeled as the two-echelon problem. In a two-echelon model, shippers collaborate over two tiers of the delivery chain: the first echelon comprises the assignment of shipments and routes from the UCC at the city border to satellites, and in the second echelon, goods are transshipped from one-tier vehicles for delivery to the final recipient. The main challenge is to synchronize the hand-over of shipments at UCCs and satellites given limited storage capacities and tight temporal restrictions.

There is a vast number of papers on routing and two-echelon problems. We point the reader to a selection of reviews and recent developments within this field. One of the first solution approaches for the two-echelon problem is provided by Crainic et al. (2011), who develop multi-start heuristics from a centralized planning perspective and build routes for the depot-to-satellite transfer and the satellite-to-customer delivery. Perboli et al. (2011) review mathematical models and heuristics for the two-echelon capacitated vehicle routing problem, and Cuda et/al. (2015) survey the state-of-the-art of two-echelon models in city logistics routing.

More recently, Grangier et al. (2016) focus on improved satellite synchronization. They do this through time window constraints and assume that there is no intermediate storage space, and they allow multiple trips on the second tier. Computational tests show that time windows have a greater impact on the solution cost than exact synchronization between the tiers. Nguyen et al. (2013) introduce waiting stations so that city freighters can stand by to enable synchronization if a first-tier vehicle has not arrived at a satellite yet. Cattaruzza et al. (2016) add release dates to make the model more realistic and complex. They assume that goods can arrive throughout the whole day at the UCC; hence, the temporal availability of shipments must be considered when creating routes. Anderluh et al. (2017) propose the usage of cargo bikes on the second tier of a two-echelon system, highlighting environmental-friendly 
transport modes in inner-city areas. Their case is based on application of a Pharmacy wholesaler in Vienna, Austria.

There are many studies on the impact of vertical collaboration on urban logistics practice that do not necessarily address OR models. Cepolina and Farina (2015) consider the transport of standardized load units ("FURBOT boxes") and discuss alternatives such as pack stations and bento boxes. The FURBOT system supports the consolidation of packages with multiple destinations into a single unit with multiple, lockable doors, ensuring the security of the freight en route to its destination. Furthermore, the boxes are palletized so that automated, low-pollution vehicles can bring them to or near their destination(s). The authors analyze the costs of the system in a case study for Lisbon, Portugal. Browne et al. (2011) assess the replacement of diesel trucks delivering freight directly from a suburban depot to customers by electric trucks and tricycles operating from a satellite in the City of London. The study concludes that for this case, using electric vehicles and a UCC can reduce the total distance traveled by $20 \%$. $\mathrm{CO}_{2}$ emissions per parcel delivered fell by $54 \%$. However, the distance traveled per parcel in the City of London delivery area rose substantially, as electric vans and tricycles have far smaller load limits in both weight and volume compared to diesel trucks.

\subsection{Using Public Transport Infrastructure for City Logistics Networks}

An interesting idea for more efficient and sustainable but also more complex realization of urban transportation, is the usage of public transportation infrastructure for logistics networks. Since the operation of public transportation systems is expensive and suffers from time-varying demand, a better utilization of publicly funded infrastructure or services seems natural.

Ghilas et al. (2013) present a mathematical model to use regularly scheduled public transit lines (such as a bus line) in combination with taxis to deliver freight. In this system, buses transport freight between transshipment locations serviced by taxis. Both the buses and the taxis carry passengers as well as freight, so that this system easily integrates into the city's existing transportation landscape. Along similar lines, though not necessarily limited to urban areas, Ghilas et al. (2016a,b,c) develop optimization approaches for an integrated solution of freight transportation with scheduled lines of public transit with public transit carrying out the core part of multi-modal transportation. As an alternative to taxis, "city freighters" can be used, as proposed in Masson et al. (2017). In this work, a bus-based system carries freight from UCCs outside of cities into city centers. The city freighters then transport freight from bus stops to its final destination. A mathematical model and heuristic solution approach are presented and applied to a case study of La Rochelle, France. The authors evaluate the system using a single bus line under varying customer demands. In low-demand settings, the total distance traveled by the collaborative system tends to be less than using a direct delivery approach; however, as demand increases, the collaborative system actually creates longer distances traveled than a direct delivery system. The key is the size of the vehicles, as the city freighters have low capacity and thus must make many trips to satisfy demand. Nonetheless, these vehicles could be cleaner and less noisy than the trucks in the direct delivery scenario. 
Rail infrastructure is often available in urban areas, but not used to realize freight deliveries. Motraghi and Marinov (2012) develop an event-based simulation model to investigate the merits of using urban light rail networks for freight transportation. They investigate two scenarios, where they add either scheduled or flexible freight trains. Dampier and Marinov (2015) discuss using a metropolitan railway network to transport freight directly to a city center for the example of Newcastle upon Tyne, UK. They compare conventional modes of transportation, inter-modal transport, city logistics, and rail transport. They claim that many cities in the UK have an existing light rail network, and there is increasing scope to use these systems for transporting freight. However, they also discuss the limitations: light rail systems cannot provide door-to-door services and lack last-mile transportation. Furthermore, some light rail systems already operate at maximum capacity to serve passenger demand.

Many papers analyzing the effectiveness of different delivery modes present concepts or empirical studies, but do not provide quantitative, OR-based approaches of using public transport infrastructure for freight deliveries. These papers provide interesting concepts and case studies for vertical collaboration and might inspire the development of quantitative approaches. For instance, Arvidsson and Browne (2013) review the success and failure of urban freight tram systems from a civil engineering perspective. Regué and Bristow (2013) survey European light rail systems for freight transport and conduct a cost-benefit analysis for two case studies in Barcelona. One study considers urban freight delivery, the other domestic waste collection. They conclude that freight transport on urban light rail networks can only be feasible if operators can exploit económies of scale, serve a minimum demand, rely on highly efficient UCCs, or exploit niche markets where current operational costs are high and little or no additional infrastructure is required. It is proposed to use obsolete passenger trams to deliver goods in Arvidsson (2010). The author creates a conceptual model of a zero emissions scheme based on freight trams and electric vehicles for the city of Gothenburg, Sweden. Alessandrini et al. (2012) investigate the sustainability of urban rail deliveries for a multi-modal UCC in Rome, Italy. The idea is to use conventional rail to carry fish from a terminal to a distribution center, and use sustainable city freighters for the last mile. As an alternative to light rail, Shen et al. (2015) explore the idea of regularly scheduled public transit buses pulling trailers with freight in containers. Some bus stations would be able to automatically unload the freight container from the trailer while passengers board and leave the bus. The authors note the system would have a rather large transport capacity and conelude that there would be cost benefits for using the system.

\subsection{Customers as Collaborators}

Customers can become vertical collaborators in last-mile transportation when logistics service providers drop off parcels at pick-up points. Following the concept termed "consumerto-package" in Savelsbergh and Van Woensel (2016), customers collect parcels and organize the transport over the last mile themselves. Pick-up points are also called self-collecting points, locker boxes, or parcel-machines in the literature. They can be designed to offer customers either exclusive pick-up or pick-up and hand-in. Morganti et al. (2014a,b) survey existing solutions in France and Germany. 
Strategically, planners need to decide where to locate pick-up points and what capacity to provide per point. For a pilot study by the Polish InPost Company, Iwan et al. (2016) investigate the usability and efficiency of pick-up points and highlight the importance of proper locations via an experimental study. In Wu et al. (2015), the authors consider how to locate pick-up points given the distribution of potential customers and their movement patterns across the city. They relate the resulting model to well-known facility location covering problems. However, as the authors point out, simply solving a clustering problem may discriminate outliers, as the center of a cluster may still not be convenient for all customers. Therefore, they propose to use a non-parametric, supervised clustering method and formulate a multi-objective optimization problem that both minimizes the distance between customers' residences and pick-up points and maximizes the immersion of pick-up points in traffic flows.

Tactically, planners need to decide how often to visit each pick-up point to deliver goods in a timely and efficient manner - this is related to service network design, as considered in Crainic et al. (2016). Here, the objective is to design an operations (or load) plan that services the expected demand while considering economic and service-quality targets. Operationally, planners have to design routes that deliver parcels to pick-up points and monitor the status of parcels waiting to be picked up, solving a pick-up and delivery problem.

The design of pick-up point networks represents an interface of OR and civil engineering. As with all location decisions, the freight movement in a city depends on the land-use in terms of shop locations and pick-up point locations, as well as on the design of transport networks feeding into these locations. Thereforé, research on freight movement models, mostly based on simulations, relates to this issue. For example, Comi and Nuzzolo (2014, 2016) present a simulation model of e-shopping and freight flows. Very little existing research explicitly focuses on designing pick-up point networks. Nevertheless, as also pointed out in Macharis and Kin (2017), they offer new opportunities for sustainable distribution. The authors particularly highlight the resulting challenge of awareness, as service providers need to analyze data to predict both demand for deliveries and pick-up times.

\subsection{Summary: Vertical Collaboration}

Vertical collaboration in urban transportation predominantly relies on letting service logistics providers decompose transportation routes into multiple tiers. Then, each coalition partner serves one or more dedicated tier. This turns the interfaces between tiers, such as the UCC or satellites, into the main point of contact, where partners' interaction determines the success of efficient deliveries. Vertical collaboration considers all levels of planning. Most importantly, strategic planning has to determine the number of tiers and the location of transshipment points. This even applies when customers are regarded as collaborators who pick up their parcels from dedicated stations. Nevertheless, within each tier, common tactical and operational problems of routing vehicles and scheduling deliveries arise.

\section{Horizontal Collaboration}

This section discusses examples of and approaches to horizontal collaboration in urban transportation. When collaborating on the horizontal level, multiple logistics service providers 
work together in the same tier of the supply chain. For example, two or more providers can offer last-mile deliveries from a UCC to the recipient's home. As partners, they can share a common distribution center, a common pool of orders, or a fleet of vehicles to reduce cost, to increase flexibility or both. In Table 2, we summarize the planning problems in this area and sort them by problem type, time horizon, and how the information exchange between coalition partners is organized.

In Cruijssen et al. (2007), the authors present one of the first surveys of horizontal logistics coalitions, concentrating on the region of Flanders, The Netherlands. As the authors point out, coalition partners aim to optimize vehicle capacity utilization, reduce empty mileage, and cut the costs of activities that are not part of their core competencies. In a similar vein, Verstrepen et al. (2009) present a framework to classify and describe the motivation for horizontal collaboration in transportation. The authors rely on empirical data from Flanders and The Netherlands. Schmoltzi and Wallenburg (2011) identify six types of horizontal cooperation, differentiated by motives, structure, and performance.

Horizontal cooperation can easily turn into a problem of "co-opetition" as described in Cruijssen et al. (2007): logistics service providers may be competitors in one market and cooperate in another market. One of the features of co-opetition is a need for decentralized control: Fully centralized planning requires a full exchange of information, which is not in the partners' interest when they are competitors in other markets. Therefore, the degree of information exchange required plays a particular role in horizontal collaboration. Most contributions consider the cost of limiting information exchange via the benchmark to an unrealistic centralized alternative.

When logistics service providers enter horizontal coalitions, they have to make a range of decisions. Strategically, they need to select a coalition or a set of partners. Tactically, partners need to define a mechanism to share cost and benefits ("pain and gain"). Operationally, they need to decide which order requests to exchange (termed "awareness" by Dahl and Derigs (2011)) and to plan the collaborative routing. When sharing order requests, Wang et al. (2014) differentiate subcontracting and exchanging requests with external partners. Here, we concentrate on the idea of exchanging requests between equal partners, as opposed to subcontracting. Morana et al. (2014) consider urban consolidation and logistics pooling from an information systems perspective and provide a French case study of decision support for coalitions. In addition, they survey a number of European UCC projects.

Horizontal collaboration in long-distance transport mostly considers so-called lanes, that is, full truckloads to be carried from one origin to one destination. By exchanging lanes, partners complement their routes and thus minimize truck re-positioning (see Manier et al. (2016)). For urban transportation, the concept of lanes as origin-destination pairs requiring a full truckload does not apply. Therefore, lane exchange approaches for truckloads as describéd, for example, by Özener et al. (2011) are not applicable. Instead, less-thantruckload requests and short distances are predominant in urban transportation. The aim of transport coalitions in this context becomes to synchronize operations in a way that minimizes the overall number of vehicles needed. 


\begin{tabular}{|c|c|c|c|c|}
\hline Area & Horizon & Problem & Information Exchange & References \\
\hline All & & Reviews & & $\begin{array}{l}\text { Cruijssen et al. (2007) } \\
\text { Verstrepen et al. (2009) } \\
\text { Schmoltzi and Wallenburg (2011) }\end{array}$ \\
\hline \multirow[t]{8}{*}{$\begin{array}{l}\text { Exchanging Or- } \\
\text { der Requests }\end{array}$} & $\mathrm{S}$ & $\begin{array}{l}\text { Carriers decide whether to enter a } \\
\text { coalition and platform provider de- } \\
\text { cides whether what type of collabo- } \\
\text { ration system to offer }\end{array}$ & $\begin{array}{l}\text { Depends on platform } \\
\text { provider decisions }\end{array}$ & Bloos and Kopfer (2011) \\
\hline & \multirow[t]{7}{*}{$\mathrm{O}$} & \multirow[t]{3}{*}{ Collaborative vehicle routing } & $\begin{array}{l}\text { Full before delivery starts: } \\
\text { orders and resources }\end{array}$ & $\begin{array}{l}\text { Ouhader and El Kyal }(2017) \\
\text { Krajewska et al. (2008)* } \\
\text { Montoya-Torres et al. }(2016)^{*} \\
\text { Muñoz-Villamizar et al. }(2017)^{*}\end{array}$ \\
\hline & & & $\begin{array}{l}\text { Full in real-time: } \\
\text { vehicles, routes }\end{array}$ & $\mathrm{hl}$ and Derigs (2011)* \\
\hline & & & Decentralized & $\begin{array}{l}\text { Vanoyermeire and Sörensen (2014) } \\
\text { Wang and Kopfer (2014) } \\
\text { Defryn et al. (2016) }\end{array}$ \\
\hline & & $\begin{array}{l}\text { "Cherry-picking" requests to offer } \\
\text { for exchange and routing }\end{array}$ & $\begin{array}{l}\text { Limite } \\
\text { quests }\end{array}$ & $\begin{array}{l}\text { Fernández et al. (2018) } \\
\text { Wang et al. }(2014)^{*} \\
\text { Dai and Chen }(2011) \\
\text { Gansterer and Hartl (2016) }\end{array}$ \\
\hline & & \multirow[t]{3}{*}{ Crowd-sourced deliveries } & & $\begin{array}{l}\text { McFarlane et al. (2016) } \\
\text { Carbone et al. (2017) } \\
\text { Rai et al. (2017) }\end{array}$ \\
\hline & & & $\begin{array}{l}\text { Full: information provided } \\
\text { via peer-to-peer platform }\end{array}$ & $\begin{array}{l}\text { Arslan et al. }(2016) \\
\text { Chen and Pan }(2016) \\
\text { Paloheimo et al. }(2016)^{*}\end{array}$ \\
\hline & & & $\begin{array}{l}\text { Dynamic: information de- } \\
\text { pénds on store status }\end{array}$ & Dayarian and Savelsbergh \\
\hline \multirow[t]{4}{*}{$\begin{array}{l}\text { Cost and Bene- } \\
\text { fit Sharing }\end{array}$} & \multirow[t]{3}{*}{$\mathrm{T}$} & $\begin{array}{l}\text { Estimate expected savings to decide } \\
\text { whether to enter the partnership }\end{array}$ & $\begin{array}{l}\text { Full before delivery starts: } \\
\text { orders and vehicles }\end{array}$ & $\begin{array}{l}\text { Lozano et al. (2013) } \\
\text { Kimms and Kozeletskyi (2016a) } \\
\text { Kimms and Kozeletskyi (2016b) }\end{array}$ \\
\hline & & \multirow[t]{2}{*}{$\begin{array}{l}\text { Compare effects of different cost or } \\
\text { savings allocation schemes }\end{array}$} & $\begin{array}{l}\text { Limited exchange on sup- } \\
\text { ply, demand, and cost }\end{array}$ & $\begin{array}{l}\text { Frisk et al. (2010)* } \\
\text { Hezarkhani et al. (2016) } \\
\text { Guajardo and Rönnqvist (2016) }\end{array}$ \\
\hline & & & Full information exchange & $\begin{array}{l}\text { Dai and Chen (2012) } \\
\text { Guajardo and Rönnqvist (2016) }\end{array}$ \\
\hline & $S \& T$ & nd cost allocation & $\begin{array}{l}\text { Limited: only selected re- } \\
\text { quests are published }\end{array}$ & $\begin{array}{l}\mathrm{Li} \text { et al. (2016c) } \\
\text { Verdonck et al. (2016) }\end{array}$ \\
\hline $\begin{array}{l}\text { Selecting Coali- } \\
\text { tion Partners }\end{array}$ & $\mathrm{S}$ & $\begin{array}{l}\text { Decide whether it is profitable to } \\
\text { enter a coalition based on potential } \\
\text { partners' characteristics }\end{array}$ & Full information & $\begin{array}{l}\text { Lozano et al. (2013), } \\
\text { Guajardo and Rönnqvist (2015)* } \\
\text { Guajardo et al. (2016)* } \\
\text { Palhazi Cuervo et al. (2016) }\end{array}$ \\
\hline \multirow[t]{3}{*}{ Ride-Sharing } & & Reviews & & Furuhata et al. (2013) \\
\hline & & \multirow[t]{2}{*}{$\begin{array}{l}\text { Decide which parcels to pick up } \\
\text { given fixed passenger requirements }\end{array}$} & $\begin{array}{l}\text { Static: a priori informa- } \\
\text { tion }\end{array}$ & $\begin{array}{l}\text { Li et al. }(2014)^{*} \\
\text { Nguyen et al. }(2015)^{*}\end{array}$ \\
\hline & & & $\begin{array}{l}\text { Dynamic: new information } \\
\text { over time }\end{array}$ & $\begin{array}{l}\mathrm{Li} \text { et al. }(2016 \mathrm{a}), \\
\mathrm{Li} \text { et al. }(2016 \mathrm{~b}) \\
\text { Do et al. }(2016)^{*} \\
\text { Ronald et al. }(2016) \\
\text { Linares et al. }(2016)\end{array}$ \\
\hline
\end{tabular}

Table 2: An overview of the horizontal collaboration literature $(\mathrm{S}=$ strategic planning, $\mathrm{T}=$ tactical planning, $\mathrm{O}=$ operational planning; ${ }^{*}$ denotes the use of real-world data). 


\subsection{Sharing Order Requests}

When logistics service providers build a horizontal coalition, they serve the same tier of the supply chain. Such a coalition can increase the efficiency of delivery for all partners by distributing requests in a way that results in distinct routes. This objective creates problems of routing and request sharing, as described for instance in Krajewska et al. (2008): Given a pool of delivery requests, which partner should fulfill which ones?

Horizontal transport coalitions are considered from the perspective of the participating service providers and from that of a provider who offers an electronic marketplace for partners to exchange requests in Bloos and Kopfer (2011). Based on this setting, they describe a set of strategic decisions and model the resulting decision-making as process chains. Notably, the authors differentiate decentralized and centralized coalitions. Decentralized coalitions are open and anonymous; they can rely on electronic marketplaces to exchange requests without giving up excessive information. Centralized coalitions are closéd systems, which can implement centrally optimal planning solutions.

The pickup and delivery problem that results from sharing requests in a coalition can be combined with paired demand or given time windows. To solve such a problem in practice, Dahl and Derigs (2011) document the development of a Decision Support System for a network of express carriers. The system models a dynamic pick-up and delivery vehicle routing problem with time windows and solves it via an indirect local search with greedy decoding. By supplying this solution to all partners, the decision support system proposes a plan for request allocation and routing.

Ouhader and El Kyal (2017) indicate synergies between operative and strategic planning by combining depot location and routing decisions for a pool of shared requests. They formulate the resulting multi-source two-echelon location routing problem for three objectives, considering total transportation, emissions, and job opportunities. This work also highlights the interface between horizontal and vertical collaboration, as carriers that serve the same segment of the delivery chain can collaborate by sharing the resources of a two-echelon network.

Wang and Kopfer (2014) assume that coalition partners are willing to offer all less-thantruckload requests they receive for exchange. For a decentralized setting with limited information flow, the authors present a new mechanism to let a coalition bundle complementary requests. This mechanism relies on the exchange of transfer prices and the iterative solution of a set partitioning problem, and allows partners to not exchange information on customer payments and cost structures. The authors aim to generate bundles that allow the individual partners' routes to come close to the efficiency of a centralized solution, which requires full information about all requests and delivery costs. Vanovermeire and Sörensen (2014) also consider the idea of consolidating transportation orders in a decentralized fashion. To that end, the authors propose to integrate cost allocation based on the Shapley value into the synchronized consolidation rather than first consolidating orders and later allocating cost. The idea of combining cost allocation and collaborative routing is also proposed in Defryn et al. (2016). In this paper, the authors consider a selective vehicle routing or orienteering problem, where coalition partners can set urgency values for their original customers before pooling all requests. By setting such urgency values, carriers can skew the information; the 
authors propose a cost-allocation mechanism based on the Shapley value to disincentivize this.

By dropping the assumption that partners are always willing to reveal all requests to the coalition, a subset of contributions considers the problem of which requests to offer for exchange. Fernández et al. (2018) formulate a similar problem, the Shared Customer Collaboration Vehicle Routing Problem, where some customers require services from more than one carrier and carriers can decide to transfer part of this demand to their alliance partners. Wang et al. (2014) propose an integrated model of operational transport planning to combine "cherry-picking" of requests for in-house execution with efficient routes for exchanged requests. Dai and Chen (2011) propose a multi-agent and auction-based framework to this end. They consider the decision problems of which request to outsource and which to acquire as mixed integer programming problems. Gansterer and Hart1 (2016) propose several strategies that let partners evaluate the set of order requests to maximize total network profit. They assume that requests are assigned among partners via Yickrey and combinatorial auctions. The authors point out that their approach is particularly well-suited for courier services, where shipments only require a fraction of the vehicle capacity.

In Montoya-Torres et al. (2016) and Muñoz-Villamizar et al. (2017), the authors evaluate the impact of a horizontal coalition of carriers sharing a fleet of electric vehicles in a case study of Bogota, Colombia. The authors evaluate the efficient relative frontier between delivery cost and environmental impact in a mathematical framework that contrasts the resulting collaborative transportation network and a traditional transportation network. To create the collaborative network, they propose a two-phase hierarchical heuristic, allocating delivery points to network members and determining the optimal routes to serve these delivery points. While evaluating the resulting overall delivery cost, they do not explicitly consider how to allocate cost and benefits among the alliance partners.

Last but not least, the idea of crowd-sourcing deliveries creates new opportunities for horizontal cooperation by allowing a large number of individual carriers to share delivery requests. The concept is framed more generally as one of customer-oriented logistics in McFarlane et al. (2016). As pøinted out in contributions that take a business perspective, such as Carbone et al. (2017), crowd-sourced delivery can present an opportunity for more sustainable transport when it uses existing infrastructure and possibly existing trips.

Nevertheless, as highlighted in Rai et al. (2017), the success of crowd-sourcing depends on information capacity and the crowds' motivation to participate in a positive manner. As described in Arslan et al. (2016), mobile technology enables peer-to-peer platforms, where parcel delivery tasks and ad-hoc drivers can be instantaneously matched. This creates a new pick-up and delivery problem as formalized by Arslan et al. (2016). As an alternative model, Dayarian and Savelsbergh consider in-store customers as potential deliverers, so that both demand for deliveries and delivery capacity are stochastic and change over time. In Chen and Pan (2016), the authors propose a framework for designing crowd-sourcing systems for last mile deliveries. Paloheimo et al. (2016) describe a Finnish application case, in which libraries rely on crowd-sourced delivery to transport books and other media to customers' homes. 


\subsection{Sharing Cost and Benefits}

The decision to enter a coalition usually rests on expectations of reducing cost or increasing revenue. In horizontal collaboration, a delivery service is not as clearly decomposed as when splitting transportation routes into multiple tiers for vertical collaboration. Therefore, the resulting problem of how to share the benefit (revenue, also referred to as gain) and cost (also referred to as pain) in horizontal collaborations has generated its own research area.

Few contributions that consider this problem focus exclusively on urban transport; however, some of the proposed methods appear applicable for horizontal collaboration in urban transportation. Examples are Frisk et al. (2010); Lozano et al. (2013) and Hezarkhani et al. (2016), who apply concepts from cooperative game theory to allocate the cost or the gain in coalitions. Dai and Chen (2012) consider the topic of profit allocation via the Shapley value, the proportional allocation concept, and the contribution of each carrier in offering and serving requests. Kimms and Kozeletskyi (2016a) and Kimms and Kozeletskyi (2016b) contribute several schemes to allocate cost in the coalition, implementing the Shapley value and the core concept from cooperative game theory.

In Hezarkhani et al. (2016), a coalition of long-distance carriers aims to avoid empty kilometers that arise from repositioning. The authors consider how such coalitions share gain, proposing several formal properties to describe schemes' fairness. Such properties are transferable to urban freight coalitions. For example, a "least instability" property prescribes that gain allocations must not motivate groups of players to form sub-coalitions. Thus, we recommend that researchers in collaborative horizontal transport not dismiss existing research on full-truckload problems. Lozano et al. (2013); Guajardo and Rönnqvist (2016) thoroughly survey further concepts.

Frisk et al. (2010) present an example of collaborative forest transport in Southern Sweden, which is picked up as an application case by later contributions, such as Guajardo et al. (2016) and Guajardo and Rönnqvist (2016). Again, while the application is far from urban transportation, the problems of cost allocation are closely related. Therefore, the analysis of different sharing mechanisms in the context of cooperative game theory, including the Shapley value, the nueleolus, séparable and non-separable costs, shadow prices and volume weights, as presented in Frisk et al. (2010), should inspire planners aiming to allocate costs in horizontal coalitions for urban transport.

In a more direct relation to problems of urban transport, Li et al. (2016c) explicitly focus on the problem of allocating cost in less-than-truckload coalitions. Furthermore, they consider the application area of perishable product retailers, which is relevant to urban transportation, where such retailers are frequently located. Retailers can collaborate by merging their less-than-truckload orders to a single haul. The authors assume that a range of transport facilities are available for booking, defining the transport facility choice problem as the first decision the coalition has to agree on. The second problem is the allocation of cost of delivery among partners.

The problem of how to allocate costs also arises when logistics service providers jointly operate distribution centers. In Verdonck et al. (2016), the authors consider the problem of cooperative facility location and provide a mixed-integer programming formulation to determine the best location for cooperative carrier facilities. They also provide profit and 
cost allocation mechanisms based on cooperative game theory. The authors present results from an experimental design based on a UK case. Shared distribution centers are closely related to the problem of UCCs; we discussed related research in Section 3.

\subsection{Selecting Coalition Partners}

The strategic decision whether or not to join a coalition or, conversely, which coalition partners to accept, is closely linked to tactical decisions of distributing cost and benefits. Therefore, several contributions consider both allocation schemes and the resulting consequences for forming coalitions. As Krajewska et al. (2008) point out, the implemented profit sharing scheme determines whether, given a set of requests, it makes sense for a carrier to enter a transport coalition. The authors use cooperative game theory to formalize the idea that no individual player will accept a coalition result that is less profitable for them than what they could achieve on their own.

Lozano et al. (2013) consider example data from Adenso-Díaz et/al. (2014) as well as randomly generated instances to evaluate the cost savings that are possible if a particular firm enters a horizontal coalition. They argue that the resulting linear model can support firms' selection of the most profitable collaboration opportunities. Guajardo and Rönnqvist (2015) rely on the example from Frisk et al. (2010) to tackle the question of which coalitions should be formed via mixed integer linear programming. Also of interest for urban transportation is the research presented in Guajardo et al / (2016), who use a Swedish example to analyze the constructive and blocking power of individual partners.

Palhazi Cuervo et al. (2016) present a simulation study that analyzes the effects of different partner characteristics on the performance of horizontal coalitions with two partners. Partners are characterized by the number of orders they have to transport, the average size of the orders, and the number of days by which they can defer orders. The authors assume that both partners solve a periodic vehicle routing problem over the horizon of multiple days using a meta-heuristic based onlocal search.

\subsection{Ride-Sharing}

When passengers and freight share rides, it is the objects rather than the providers of transportation that collaborate horizontally. The idea, e.g., in the form of a shared taxi service, has been long discussed in the literature. Furuhata et al. (2013) provide an overview of references and examples from practice. Recent contributions consider concepts that let passengers and freight share taxis within variants of multiple pick-up and delivery vehicle routing problems. Li et al. (2014) consider a taxi-based ride sharing system, introduce mathematical models for static and dynamic collaborative freight cases, and provide an adaptive large neighborhood search in Li et al. (2016a). The authors dub this the "share-aride" problem and further consider stochastic problem aspects in Li et al. (2016b). Nguyen et al. (2015) extend the model of Li et al. (2014) to support a real road network, as well as including constraints to prevent passenger trips from being interrupted by freight pickups or deliveries. The authors provide heuristics to solve the model quickly in practice and provide experimental results on data from a taxi company in Tokyo, Japan. Do et al. 
(2016) re-examine the dynamic case presented in Li et al. (2016b) and extend both this work and Nguyen et al. (2015) to consider traffic congestion.

Ronald et al. (2016) create a simulation of a collaborative parcel carrying system using taxis and vans to carry both passengers and freight. They define two levels of collaboration. In the first, vans are shared between businesses and taxis carry passengers separately. In the second, called "co-modality", vans and taxis can carry either passengers or parcels. The authors show that the co-modal setting is beneficial for both passengers and parcels, reducing the waiting time for both of them over a non- "co-modal" system. Linares et al. (2016) also present a simulation system capable of modeling the dynamics of ride-sharing for both passengers and parcels sharing vehicles.

\subsection{Summary: Horizontal Collaboration}

The question of centralized or decentralized planning via different degrees of information exchange lies at the heart of horizontal collaboration: When logistics service providers jointly serve the same tier, such as the last mile from a UCC to a customer, problems of co-opetition arise. As providers may be partners in one market but continue to compete in another market, exchanging full information on customer requests and transportation costs may not be desirable or even feasible.

Finding cost-efficient routes for the resulting pick-up and delivery problems is the most common coalition objective. However, since not all information required for solving the central problem may be available, performance depends not only on the routing algorithm determining the short-term operations; instead, strategic partner choice and tactical guidelines for the distribution of cost and benefits become decisive factors. In addition, assigning requests to partners is a major challenge when not all partners are willing to pool all requests. To overcome these challenges, recent research applies concepts of cooperative game theory and simulation modeling.

\section{Real-world Collaborative Urban Transportation}

Urban transportation systems increasingly contain some form of collaboration. Although many innovative concepts have met with failure in practice, several remain in operation today. This section surveys concepts, prototypes, and realized projects to gain insight on what worked and what did not. Implementing collaborative transport systems in urban environments requires both novel enabling technologies and political and regulatory support. While the previous sections focused on theoretical models from the domain of OR, this section considers models, technology, and policy, as all impact the success or failure of collaborative systems in practice.

A particular focus of this section is potential reasons for the success or failure of projects. We investigate multiple systems on an individual basis to try to determine what makes the system unique, as well as what led to the system's success or failure. As we show in this section, user acceptance of a collaborative system is paramount, as is political acceptance. We provide analysis regarding these criteria whenever possible, but note that for many systems not all aspects are known due to company secrecy. 


\begin{tabular}{ccccccc}
\hline System & Location & Impl? & Itype & Vehicle & Btype & Status \\
\hline CarGoTram & Dresden, DE & R & SLR & Freight LR & B2B & OP \\
CargoTram & Zürich, CH & R & SLR & Custom LR & B2C & OP \\
Monoprix & Paris, FR & R & SLR & Freight LR & B2B & OP? \\
TramFret & Paris, FR & R & SLR & Freight LR & B2B & OP \\
Bremer CitiPost & Bremen, DE & R & PF & LR & Mail & OP \\
Mail Tram & (Mult.), DE & R & PF & LR & Mail & NLO \\
Border Courier Service & Scotland, UK & R & PF & Bus & Any & NLO \\
CityCargo & Amsterdam, NL & P & SLR & Freight LR & B2B & NLO \\
GüterBim & Vienna, AT & P & SLR & Freight LR & B2B & NLO \\
US Patent \#6,240,362 & USA & C & PF & Custom Bus & Any & NO \\
\hline
\end{tabular}

Table 3: An overview of realized (R), prototyped $(\mathrm{P})$ and conceptualized $(\mathrm{C})$ collaborative transportation systems. We categorize infrastructure types (IType) into shared light rail (SLR), passengers and freight in the same vehicle (PF). Light rail is abbreviated with LR. The column Btype gives the type of business the system aims to serve. We describe several current system statuses: Operational (OP), no longer operational (NLO), never operational (NO). Finally, we give the most current information we ean, with uncertainty indicated with a question mark.

Indeed, city logistics systems have had a number of failures in practice, as highlighted by Woodburn et al. (2015). They claim that while there were many trials and experiments of UCCs in European cities, not many have survived the trial phase. Our investigation in this section confirms this notion: we count eight modern systems in Europe, of which only four are still operational. While a $50 \%$ survival rate may seem promising, we note that the more ambitious systems, i.e., those that would carry high cargo volumes, are no longer operational.

We focus on documented, realized systems, but note that many systems in practice are a long way off from being truly collaborative. The systems we highlight, however, have collaborative components and form a basis for future innovation. Although in the previous sections of this work we have/classified systems as being either vertical or horizontal, real world systems are much harder to cleanly partition into these categories. On the one hand, it can be argued that the systems we present are horizontal because of shared infrastructure and occasionally due to multiple stakeholders. On the other hand, the systems can be considered to be vertical because they are usually a single part of a multi-echelon logistics chain. Due to this, we separate systems into road- and rail-based systems and highlight the type of collaboration and the primary planning challenges involved.

We summarize the systems and ideas presented in this section in Table 3. We acknowledge an inherent bias in the systems we present, as we can only report systems that have been reported in languages we understand. It is conceivable that collaborative systems exist that have not been addressed in the literature and are also not in an English language publication, but unfortunately we have no way of including these in this study.

Several collaborative transportation systems have been attempted in European cities, carrying trash, mail, and freight along with passengers. The collaboration of such systems can be divided into two types: shared space with centralized control, and shared vehicles. Shared space systems use mobile consolidation centers and thus "share" space with city residents. In shared infrastructure systems, passenger and freight trains both use the same tracks, but the vehicles themselves are separate. In contrast, shared vehicle systems can 
combine freight and passenger cars, or can even carry freight within a passenger area.

\subsection{Shared Rail Infrastructure with Centralized Control}

Several attempts have been made to let passengers and freight share common rail infrastructure in real-world systems. A key aspect of these systems is the centralized control, as there is a single operator coordinating freight deliveries from consolidation centers outside the urban area and bringing them on an existing (and thus relatively cheap to use) infrastructure. We asked one of the project coordinators of one of the systems in this section about what contributed to the success of the system. To this end, the existing, shared light rail infrastructure was identified as a key point. In addition, the planner emphasized political will for the system, a simple origin-destination network structure, and avoiding in-system trans-shipments.

Marinov et al. (2013) provide a detailed overview of existing freight services operated on tram networks and particularly mention the systems discussed in this section. They distinguish projects by project owners, funding, the size of projects, type of goods delivered, types of customers, and the current status. To our knowledge, three out of five systems described here are still operational. Nonetheless, the other two are not considered failures.

The CarGoTram in Dresden, Germany, consists of a five-piece train that carries car parts from a city-wide transportation hub to a Volkswagen factory in the city (Arvidsson and Browne (2013); Eltis (2017a)). A key to the system's success is its almost exclusive reliance on Dresden's existing light rail infrastructure, requiring only 800 meters of extra track to be built. Additionally, the project's partnership with DVB, who operate the public transport in Dresden, likely contributed to its success. The main costs for the system, on the order of several million Euros, are related to the construction of the train. The system also has a clear origin and destination of freight and only runs several times a day. The system has had political acceptance from its inception.

In Zurich, Switzerland, the similarly named CargoTram is a collaborative effort between tram operator VBZ and waste collection agency Entsorgung und Recycling Zürich. It carries bulky waste and electronic waste from pick-up locations in residential neighborhoods to a central processing facility (Moglestue, 2013). Similarly to the Dresden system, the Zurich CargoTram uses existing tracks. Furthermore, the waste-carrying train was constructed mainly using spare vehicles and parts, making it particularly cost-effective - on the order of only tens of thousands of Euros. The Zurich CargoTram's high user acceptance and utilization make it a success (Haffner, 2013).

The GüterBim system was implemented in Vienna, Austria in 2004/2005 as part of a temporary research project. While considered a "success" by the city government (Fochler, 2005), the system was not continued after the project's completion. GüterBim consisted of a freight unit that traveled on Vienna's existing passenger light rail infrastructure. Vienna is particularly well-suited for collaborative freight units because of its extensive light rail network. Somewhat regrettably, delivery recipients, such as stores and restaurants in the city, showed little interest in the system according to newspaper reports published after the trial ended (Ziegler, 2007). GüterBim was significantly more expensive than, for instance, 
the Zurich CargoTram, costing roughly 1.4 million EUR in total. Furthermore, GüterBim lacked a mechanism for quickly loading and unloading freight.

In contrast to the systems in Dresden, Zurich and Vienna, in Amsterdam, The Netherlands, the CityCargo initiative went bankrupt before it could be fully implemented (Eltis, 2017b). The system would have been an expanded version of the Dresden CargoTram regarding technical construction, but would have resembled GüterBim in operation. It included freight trains using existing tracks along with new sections to deliver goods to stores and markets in the crowded city center, carrying them from UCCs located in less populated areas. In spite of the eventual bankruptcy, we consider this system as realized, as an initial prototype proved it could be effective. However, after this initial success, the project fell victim to politics, as the city insisted new track be financed by the company rather than the public. Arvidsson and Browne (2013) investigate the failure of the CityCargo initiative, identifying potential barriers to the successful implementation of a combined passenger and freight tram system. These include interference with personal traffic, scale, conflicting objectives among stakeholders, and stakeholder involvement. Such issues call for a high degree of cooperation and willingness to engage with public and private stakeholders. Therefore, any investment decision must consider them.

The Paris TramFret project explored loading freight into a light rail system in 2011 (Danard and Janin, 2016). Gonzalez-Feliu (2014) analyzes costs and benefits of urban railway logistics based on a case study of this freight tram. They conclude that urban railway logistics is an interesting alternative for urban freight delivery, but that it needs to be planned and aligned among stakeholders. Furthermore, the project found that a collaborative light rail system would not negatively impact passenger transport. The TramFret system also envisioned using a specialized container for quick loading and unloading. The project appears to have had significant political support and was presented during the COP21 conference on climate change in Paris (Dufour). The system was first put into operation in June, 2017 (Barrow, 2017).

Overlapping responsibilities and requirements between the public and private sector form a critical component of efforts to integrate passenger and freight transport. In other words, the interests of those who own public transport infrastructure and those who might wish to use it must align, By evaluating the cases of CarGoTram, CargoTram, CityCargo, Monoprix, and a proposed Newcastle site, Motraghi (2013) highlights that even feasible and potentially beneficial systems depend on significant up-front investment costs. Therefore, they are contingent upon political support as reflected in incentives, supporting or enabling legislation and stated commitment of policy makers. Obtaining such political support is not inconceivable: trialled and extant systems, such as CarGoTram, demonstrate measurable benefits, including emissions reductions and removal of heavy goods vehicles from urban roadways (Arvidsson and Browne, 2013; Regué and Bristow, 2012). Modeled scenarios reflect similar potential benefits in terms of reduction of emissions, congestion, noise, and other negative externalities of freight transportation (Zych, 2014; Alessandrini et al., 2012). Such benefits may encourage investment in and support of collaborative transportation in urban areas, particularly if designed such that access to external funding is possible (Mingardo, 2008). 


\subsection{Shared Vehicles with Centralized Control}

One of the earliest instances of urban public transportation moving both passengers and freight is the Poststraßenbahn, or "Mail Tram" (Matthaei, 2017). Several German cities used such trams during the late 1800s and early 1900s to carry bags of mail in addition to passengers. The trams primarily served hubs, where mail was taken and then forwarded to its final destination. Mail was also accepted in boxes on the train, a tradition that is continued today in Bremen, Germany, where the company CITIPOST has placed mail collection bins on the city's trams (CITIPOST GmbH, 2017).

The idea of using passenger vehicles to carry freight is not confined to urban environments. The Border Courier Service in Scotland transported medical supplies in addition to passengers as early as 1979 (Robinson, 1995). Such systems aim to offer better passenger and freight services in areas with low population density that would otherwise have poor connections to other regions. According to Robinson (1995), the border courier service physically separated freight from passengers in a specialized compartment of mini coaches.

In suburban and rural environments, collaborative systems can be cost-efficiently implemented. This is because, in such environments, there is too little demand being in place to support a full passenger or freight network. In urban environments, the opposite problem could arise: a system that combines passenger and freight transport might lack sufficient room for freight. Additionally, urban passenger flows may not leave sufficient time to move freight on and off the vehicles, inducing delays.

In 2007, a vertical coalition of light rail and gas-powered vans intended to handle deliveries for the Paris grocery store Monoprix (Charlier, 2008). The train delivered cargo to a UCC, from which it was transshipped onto natural gas powered vans. We were unable to find information indicating whether the Monoprix system was considered a success or whether it is still in operation.

\subsection{Innovative Collaboration with Decentralized Control}

A number of start-ups have begun exploring innovative business models related to the sharing economy. Hamari et al. (2015) survey reasons for people to participate in the sharing economy. They define the concept as "[t]he peer-to-peer-based activity of obtaining, giving, or sharing the access to goods and services, coordinated through community-based online services". So far, this section mostly explored the ideas and systems that rely on centralized control, i.e, there is a governing entity controls service operations. In contrast, the sharing economy is decentralized and could provide new avenues for collaborative freight in urban environments.

Rougès and Montreuil (2014) review start-ups and companies that rely on crowd sourcing to deliver freight. The authors address a wide variety of business models, ranging from Uberlike delivery models to people assisting other people with international deliveries through planes. The survey considers pricing and societal benefits, generating a typology of business models. UberRush (Uber Technologies, Inc., 2017) exemplifies an app-based service that connects those who want to send packages within an urban area with drivers. To our knowledge, UberRush is currently separate from Uber's passenger services. However, it seems like an intuitive next step to allow freight and passengers to share Uber vehicles. 
Apps and business models centered around the sharing economy are turning into an important aspect of collaborative freight. For example, when a collaborative light rail system transports freight brought into the city, last-mile deliveries could be arranged via such models. Following the ideas explored, for instance, in Archetti et al. (2016), some drivers may be dedicated couriers, whereas others could occasionally contribute. An app could notify occasional drivers near the station and the delivery point and motivate them to perform a delivery.

\subsection{Takeaways on the Evolution of Collaborative Transportation}

Considering real-world examples yields two major takeaways. First and foremost, political considerations matter. While complex, the many aspects of the logistics of combining freight and passenger transport in an urban environment are well-described and addressed in the literature. Yet, the political and regulatory feasibility of this endeavor is less well understood. Reflecting this, from a three-round Delphi study with 34 transport experts participating, Cochrane et al. (2017) conclude that organizational and institutional barriers to enable freight and passengers to share public transport may be more difficult to overcome than technical challenges. Some of the key challenges identified in this Toronto-based study included: financing, capacity, stakeholder coordination, resistance from stakeholders (including freight carriers, transit agencies, unions and others), and dealing with resistance from politicians and decision-makers.

Second, new collaborative transport concepts must address the problem of growing delivery times. Collaborative freight systems often add an extra edge to logistics networks, which increases the time it takes for freight to reach its destination. This problem is especially relevant when systems include manual loading and unloading of freight. Emerging concepts, such as FURBOT, will likely offer partially or fully automated transshipment of freight at consolidation centers and during pickup and delivery. Here, theoretical advances in areas such as routing and request sharing could improve real-world performance.

\section{Future OR Challenges}

Since collaborative urban transportation systems are still being explored, many OR problems in this area have been not at all or only partially addressed. Comparing real-world applications of collaborative urban transportation (Section 5) to the theoretical advances surveyed in Sections 3 and 4 highlights a number of future OR challenges. These arise at all levels of planning, as described in this section.

\subsection{Strategic Planning}

Strengthen Stakeholder Involvement. To support the formation of coalitions, OR can link to information systems to build decision support systems that include multiple stakeholders and foster trust. For example, Gonzalez-Feliu and Morana (2014) present a hierarchical dashboard to support joint decision making for carrier alliances from a group decision perspective. To enhance trust as considered through behavioral effects in Daudi et al. (2016), 
future contributions need to consider the multi-criteria aspects of diverse stakeholders for urban transport, as exemplified by Estrada and Roca-Riu (2017), Gonzalez-Feliu et al. (2013), Hammervoll and Bø (2010) or Le Pira et al. (2017) - the latter using agent-based simulation.

Measure Collaboration Performance. To increase the acceptance and success of collaborations, future contributions need to strengthen research on measuring the empirical effects of collaboration beyond simulation experiments, for example via data envelopment analysis as proposed in Cruijssen et al. (2010). Furthermore, advanced analytics could help to critically account for customer choice and further demand modeling, as customers may react more or less positively to carriers forming coalitions, see Tavasszy et al. (2012).

Enable Fourth-Party-Involvement. As pointed out in Section 4, horizontal collaborations inherently contain aspects of co-opetition. Therefore, joint planning is always at the risk of becoming a victim of competition instead of fostering collaboration. Research on involving a fourth party could minimize this effect. Calls for such a fourth party are voiced, for example, in Hingley et al. (2011) or Allen et al. (2017). In this regard, corporate governance as described in Agrell et al. (2017) may also be relevant. Another way to extend the reach of coalitions would be to extend OR models to enable collaboration with city authorities. Köster et al. (2015) present a routing approach where logistics service providers know the signal plans of the city's traffic signals and can anticipate them in the routing of their delivery vehicles.

Enable Multimodal Network Design. The planning of new infrastructure within, e.g., facility location problems, could consider freight vehicles or combined vehicles within a mathematical model or heuristic. To the best of our knowledge, existing models in an urban context do not consider collaborative settings (e.g., in location routing (Nagy and Salhi, 2007)). In some problem settings, existing models may be applicable, such as when passengers and freight exclusively share light rail infrastructure and when UCC locations are given in advance (e.g., Cepolina and Farina (2015)). This would also encourage more inter-modal transport on the last mile, as argued for long-distance transport in Colicchia et al. (2017). In addition, concepts of synchromodality can be considered as presented in Dong et al. (2016), potentially letting coalition partners share the cost of the resulting required investments as theoretically analyzed in Roma and Perrone (2016).

Integrated Facility Location and Network Design. Network design has been extensively considered in a number of applications, in particular for various types of transport networks (Guihaire and Hao, 2008). Integrated facility location and network design problems have previously been considered for general distribution networks; however, especially the case of light rail has not been modeled. Given the prevalence of light rail systems in real-world examples, this could be a particularly interesting line of research. For example, the exclusive usage of tracks creates constraints that are not present in existing contributions, which usually consider a road network. When road-based buses combine passenger and freight transport, as in, e.g., James (2001), existing models may be sufficient. 
Optimize Vehicle and Fleet Design. A further strategic problem is the design of collaborative freight vehicles and the compilation of effective fleets. For example, mathematical optimization models could determine the percentage of a vehicle that should be designed for freight transportation when considering fleets of traditional freight vehicles. This is a highly stochastic problem, as the amount of demand, number of passengers, and amount of time to load and unload freight are uncertain. In recent years, there have additionally been multiple approaches considered for more innovative delivery technologies in urban areas using non-conventional vehicles. For example, Slabinac (2016) surveyed innovative solutions for last-mile delivery in Europe, in particular considering electric cargo bikes, parcel copters, cargo caps (underground tunnels for automated delivery pods), and sélf-driving parcels. Such innovations could introduce further complexities regarding the potential fleet mix, and how it relates to the underlying transport infrastructure. Additionally, once vehicle types (whether conventional, innovative, or mixed) are determined, the fleet mix can be optimized, even potentially in combination with station locations, as is done for a rail line in Repolho et al. (2016). Another aspect of vehicle design is considering opportunities of autonomous vehicles in collaborative transport, as pointed out by Stocker and Shaheen (2017).

Incentivize Collaboration. In regards to the sharing economy, it remains to be seen to what degree new OR models at the strategic level are required. Pick-up and delivery problems, as well as fleet sizing problems, are well studied in the literature. Whether cars carry passengers or freight, or both, does not seem to pose a major issue for current techniques, but specific infrastructure or business model requirements may result in new questions. However, future research should consider aspects of customer aeceptance and incentives for crowd-shipping, following research as outlined in Punel and Stathopoulos (2017). This could, for instance, mean exploring the use of social networks of customers as indicated in Devari et al. (2017).

Model Macro-Level Effects. On a high level of planning, a significant increase in transport collaborations can be expected to have macro-level implications as indicated in Saeedi et al. (2017). With regard to such effects, researchers should also account for effects of cooperation complexity, as suggested for instance in Schmoltzi and Wallenburg (2012).

\subsection{Tactical Planning}

Account for Risk and Flexibility. As already argued in relevant contributions for supply chain management (König and Spinler, 2016), collaboration increases firms' risk exposure. Therefore, future models of collaborative transport need to take risk-related aspects for both coalition partners and customers into account. Somewhat related is the idea of introducing additional flexibility to last-mile transport, e.g., via customer incentives, to reap benefits as proposed in Vanovermeire et al. (2014). To increase flexibility, research could also consider opportunities of keeping coalitions dynamic, as proposed for general supply chain networks by Seok and Nof (2014). This would turn the formation of coalitions from a strategic to a tactical problem. 
Improve Vehicle Deployment. At the tactical level, a system requires planners to decide on which lines to deploy vehicles. This problem is addressed for passenger rapid transit (rail) networks in Cadarso and Marín (2014) and handles uncertainty. Extending this problem to consider collaborative systems could involve considering not only the effects of stochastic freight demand, but also the flexible transport of freight to different UCCs. The problem is mainly interesting for heterogeneous fleets, when some vehicles may be restricted to certain types of freight or to passengers, or may have different carrying capacities.

Improve Collaborative Scheduling. Planning schedules for a collaborative transit system could require new models and methods. For example, combining freight and passenger handling creates questions as to how to handle longer stop times at UCCs. Schedules need to accommodate freight and passenger demand so that capacities can be fully utilized. Given the wide range of literature on timetabling for transit networks (Guihaire and Hao, 2008), especially in terms of delay robustness, existing models and approaches can be adapted to handle the highly stochastic case of collaborative freight. The schedule planning could further consider bi/multi-echelon inventory routing so that the inventory capacity and costs could be synced with the planned schedule. Another extension of "standard" schedule planning would be to mix scheduled services with extra-1oaders for freight to help handle peak demand.

\subsection{Operational Planning}

Manage Demand to Balance System Load. For operational planning to ease system congestion, collaborative systems could rely on revenue management and dynamic pricing as described in Pellegrini and Rodriguez (2013) with regard to air and rail transport. Deliberate pricing or slot allocation can nudge shippers or customers toward less popular routes or transport times. While public transit generally relies on static pricing, the freight pricing in such systems need not be similarly restricted. The problem could be particularly interesting when passengers and freight share space or infrastructure, such as in a vehicle with an adjustable freight storage area.

Enable Collaborative Storage and Packing. In systems where a dedicated freight area should accommodate multiple packages/items, the question arises of how to pack them efficiently. Packing problems have been widely studied in various contexts (Wäscher et al., 2007). However, if a collaborative freight system includes automated loading and unloading, new restrictions on package shapes and how they can be packed could arise, thus future work in this area may need to collaborate closely with engineers.

Enable Collaborative Disruption Planning. Disruption planning and schedule recovery also represent important challenges for urban transport, and have been studied in a general railway (Jespersen-Groth et al., 2009) and urban context (Darmanin et al., 2010). Recovery actions in the collaborative setting could be different than in a pure passenger setting. For example, freight could be kept on a delayed vehicle until its next service, something that we would not recommend doing with passengers. 
Integrate Information Management. When considering planning from an OR perspective, challenges of information management, as summarized under the term 'collaborative transport management' in Okdinawati et al. (2015) should not be forgotten. Related ideas are exemplified for ride-sharing in Földes and Csiszár (2017). This could also mean applying predictive analytics to the data available to coalition partners in urban transport as indicated by Ilie-Zudor et al. (2015) for general less-than-truckload transport.

Combine Vertical and Horizontal Collaboration. Finally, case studies such as Simmer et al. (2017) or Mason et al. (2007) call for more closely integrated vertical and horizontal collaboration to fully achieve concepts of the Physical Internet. To achieve this, operational planning models need to be extended beyond the categories this literature survey followed.

\section{Conclusion}

This contribution presented a review of collaborative urban freight systems, discussing both related work from the literature as well as real-world systems. With urban areas continuing to become more and more crowded, innovative ideas for transporting passengers and freight are becoming increasingly important for keeping cities attractive and livable.

We analyzed systems that employ a range of modes for urban transportation, including buses, trams, taxis and even some vehicles that, at this point, are still on the drawing board. We identified two key types of collaboration, horizontal and vertical, and examine related work in those areas that has been or could be used in collaborative systems. In particular, we considered strategic, tactical, and operational planning horizons as well as different degrees of information exchange and planning centralization. However, much work within the fields of $\mathrm{OR}$ and civil engineering remains to be done, as highlighted in our overview of open challenges.

\section{Acknowledgments}

We thank the Leibniz Association for sponsoring the Dagstuhl Seminar 16091, at which the work presented here was initiated. We also thank Leena Suhl for her comments on an early version of this work. Finally, we thank the anonymous reviewers for the constructive comments.

\section{References}

Adenso-Díaz, B., Lozano, S., Moreno, P., 2014. Analysis of the synergies of merging multi-company transportation needs. Transportmetrica A: Transport Science 10, 533-547. doi:10.1080/23249935.2013. 797518.

Agatz, N., Erera, A., Savelsbergh, M., Wang, X., 2012. Optimization for dynamic ride-sharing: A review. European Journal of Operational Research 223, 295-303.

Agrell, P.J., Lundin, J., Norrman, A., 2017. Supply chain management: Horizontal carrier coordination through cooperative governance structures. International Journal of Production Economics 194, 59-72.

Alessandrini, A., Site, P., Filippi, F., Salucci, M., 2012. Using rail to make urban freight distribution more sustainable. European Transport - Trasporti Europei 50. 
Allen, J., Bektaş, T., Cherrett, T., Friday, A., McLeod, F., Piecyk, M., Piotrowska, M., Zaltz Austwick, M., 2017. Enabling a freight traffic controller for collaborative multidrop urban logistics: Practical and theoretical challenges. Transportation Research Record: Journal of the Transportation Research Board , 77-84.

Anderluh, A., Hemmelmayr, V.C., Nolz, P.C., 2017. Synchronizing vans and cargo bikes in a city distribution network. Central European Journal of Operations Research 25, 345-376.

Archetti, C., Savelsbergh, M., Speranza, M.G., 2016. The vehicle routing problem with occasional drivers. European Journal of Operational Research 254, 472-480. doi:10.1016/j .e jor .2016.03.049.

Arslan, A., Agatz, N., Kroon, L., Zuidwijk, R., 2016. Crowdsourced delivery-a pickup and delivery problem with ad-hoc drivers. SSRN Electronic Journal , 1-29.

Arvidsson, N., 2010. New perspectives on sustainable urban freight distribution: A potential zero emission concept using electric vehicles on trams, in: Proceedings of the 12th World Conference on Transport Research, pp. 11-15.

Arvidsson, N., Browne, M., 2013. A review of the success and failure of tram systems to carry urban freight: the implications for a low emission intermodal solution using electric vehicles on trams. European Transport/Trasporti Europei 54, 1825-3997.

Barrow, K., 2017. Freight tram trial delivers for retailer. http://www.railjournal.com/index.php/lightrail/freight-tram-trial-delivers-for-retailer.html. Accessed June 2017.

Bektaş, T., Crainic, T.G., Van Woensel, T., 2017. From managing urban freight to smart city logistics networks, in: Network Design and Optimization for Smart Cities. World Scientific, pp. 143-188.

Bloos, M., Kopfer, H., 2011. On the formation of operational transport collaboration systems, in: Dynamics in Logistics. Springer, pp. 191-201.

Browne, M., Allen, J., Leonardi, J., 2011. Evaluating the use of an urban consolidation centre and electric vehicles in central London. IATSS Research 35, 1-6. doi:10.1016/j.iatssr.2011.06.002.

Browne, M., Allen, J., Nemoto, T., Patier, D., Vissér, J., 2012. Reducing social and environmental impacts of urban freight transport: A review of some major cities. Procedia - Social and Behavioral Sciences 39, 19-33. doi:10.1016/j.sbspro.2012.03.088.

Browne, M., Allen, J., Nemoto, T., Visser, J., 2010. Light goods vehicles in urban areas. Procedia-Social and Behavioral Sciences 2, 5911-5919.

Cadarso, L., Marín, A., 2014. Improving robustness of rolling stock circulations in rapid transit networks. Computers \& Operations Research 51, 146 - 159. URL: http://www.sciencedirect.com/science/ article/pii/S0305054814001361, doi:http://dx.doi.org/10.1016/j.cor.2014.05.007.

Carbone, V., Rouquet, A., Roussat, C., 2017. The rise of crowd logistics: A new way to co-create logistics value. Journal of Business Logistics 38, 238-252.

Cattaruzza, D., Absi, N., Feillet, D., 2016. The multi-trip vehicle routing problem with time windows and release dates. Transportation Science 50, 676-693.

Cattaruzza, D., Absi, N. Feillet, D., González-Feliu, J., 2015. Vehicle routing problems for city logistics. EURO Journal on Transportation and Logistics 6, 51-79.

Cepolina, E.M., Farina, A., 2015. A new urban freight distribution scheme and an optimization methodology for reducing its overall cost. European Transport Research Review 7, 1-14.

Charlier, L., 2008. Paris pushes urban freight experiment. Railway Gazette: http://www.railwaygazette. $\mathrm{com} /$ news/single-view/view/paris-pushes-urban-freight-experiment.html. Accessed May 2017.

Chen, C., Pan, S., 2016. Using the crowd of taxis to last mile delivery in e-commerce: a methodological research, in: Service Orientation in Holonic and Multi-Agent Manufacturing. Springer, pp. 61-70.

CITIPOST GmbH, 2017. Privatkunden / bremen / home. URL: http://www.citipost.de/Bremen/ Privatkunden. accessed June 2017.

Cochrane, K., Saxe, S., Roorda, M.J., Shalaby, A., 2017. Moving freight on public transit: Best practices, challenges, and opportunities. International Journal of Sustainable Transportation 11, 120-132.

Colicchia, C., Creazza, A., Dallari, F., 2017. Lean and green supply chain management through intermodal transport: insights from the fast moving consumer goods industry. Production Planning \& Control 28, $321-334$. 
Comi, A., Nuzzolo, A., 2014. Simulating urban freight flows with combined shopping and restocking demand models. Procedia-Social and Behavioral Sciences 125, 49-61.

Comi, A., Nuzzolo, A., 2016. Exploring the relationships between e-shopping attitudes and urban freight transport. Transportation Research Procedia 12, 399-412. doi:10.1016/j.trpro.2016.02.075.

Crainic, T.G., Hewitt, M., Toulouse, M., Vu, D.M., 2016. Service network design with resource constraints. Transportation Science 50, 1380-1393. doi:10.1287/trsc. 2014.0525.

Crainic, T.G., Mancini, S., Perboli, G., Tadei, R., 2011. Multi-start heuristics for the two-echelon vehicle routing problem. Proceedings of Evolutionary Computation in Combinatorial Optimization, 179-190.

Cruijssen, F., Cools, M., Dullaert, W., 2007. Horizontal cooperation in logistics: Opportunities and impediments. Transportation Research Part E: Logistics and Transportation Review 43, $129-142$. doi:10.1016/j.tre.2005.09.007.

Cruijssen, F., Dullaert, W., Joro, T., 2010. Freight transportation efficiency through horizontal cooperation in Flanders. International Journal of Logistics: Research and Applications 13, 161-178.

Cuda, R., Guastaroba, G., Speranza, M., 2015. A survey on two-echelon routing problems. Computers \& Operations Research 55, 185-199. doi:10.1016/j.cor.2014.06.008.

Dahl, S., Derigs, U., 2011. Cooperative planning in express carrier networks - an empirical study on the effectiveness of a real-time decision support system. Decision Support Systems 51, 620-626. doi:10.1016/ j.dss.2011.02.018.

Dai, B., Chen, H., 2011. A multi-agent and auction-based framework and approach for carrier collaboration. Logistics Research 3, 101-120. doi:10.1007/s12159-011-0046-9.

Dai, B., Chen, H., 2012. Profit allocation mechanisms for carrier collaboration in pickup and delivery service. Computers \& Industrial Engineering 62, 633-643. doi:10.1016/j.cie.2011.11.029.

Dampier, A., Marinov, M., 2015. A study of the feasibility and potential implementation of metro-based freight transportation in Newcastle upon Tyne. Urban Rail Transit 1, 164-182.

Danard, J., Janin, K., 2016. Tramfret: Tramway recyclé pour une logistique urbaine durable énergétiquement efficace. http://tramfret.com/. Accessed May 2017.

Darmanin, T., Lim, C., Gan, H., 2010. Public railway disruption recovery planning: a new recovery strategy for metro train Melbourne, in: Proceedings of the 11th Asia pacific industrial engineering and management systems conference.

Daudi, M., Hauge, J.B., Thoben, K.D., 2016. Behavioral factors influencing partner trust in logistics collaboration: a review. Logistics Research 9, 19.

Dayarian, I., Savelsbergh, M., . Crowdshipping and Same-day Delivery: Employing In-store Customers to Deliver Online Orders. Technical Report. Georgia Institute of Technology.

Defryn, C., Sörensen, K., Cornelissens, T., 2016. The selective vehicle routing problem in a collaborative environment. European Journal of Operational Research 250, 400-411.

Devari, A., Nikolaev, A.G., He, Q., 2017. Crowdsourcing the last mile delivery of online orders by exploiting the social networks of retail store customers. Transportation Research Part E: Logistics and Transportation Review 105, 105-122.

Do, P.T., Nghiem, N.V.D., Nguyen, N.Q., Nguyen, D.N., 2016. A practical dynamic share-a-ride problem with speed windows for Tokyo city, in: 2016 Eighth International Conference on Knowledge and Systems Engineering (KSE), pp. 55-60. doi:10.1109/KSE.2016.7758029.

Dong, C., Boute, R., McKinnon, A., Verelst, M., 2016. Investigating synchromodality from a supply chain perspective. Transportation Research Part D: Transport and Environment URL: http://dx.doi.org/ 10.1016/j.trd.2017.05.011.

Dufour, M., . Un an aprés la cop 21, oú en est le tram-fret á Saint-Etienne? http://www.activradio. com/un-an-apres-la-cop-21-ou-en-est-le-tram-fret-a-saint-etienne/. Accessed May 2017.

van Duin, J., van Kolck, A., Anand, N., Tavasszy, L.A., Taniguchi, E., 2012. Towards an agent-based modelling approach for the evaluation of dynamic usage of urban distribution centres. Procedia - Social and Behavioral Sciences 39, 333 - 348. URL: http://www.sciencedirect.com/science/article/pii/ S1877042812005794, doi:http://dx.doi.org/10.1016/j.sbspro.2012.03.112.

Eltis: The Urban mobility observatory, 2015a. Cleaner cargo distribution in Dresden (Germany). http:// 
www.eltis.org/discover/case-studies/cleaner-cargo-distribution-dresden-germany. Accessed May 2017.

Eltis: The Urban mobility observatory, 2015b. Delivering goods by cargo tram in Amsterdam (The Netherlands). http://www .eltis.org/discover/case-studies/delivering-goods-cargo-tramamsterdam-netherlands. Accessed May 2017.

Estrada, M., Roca-Riu, M., 2017. Stakeholders profitability of carrier-led consolidation strategies in urban goods distribution. Transportation Research Part E: Logistics and Transportation Review 104, $165-188$.

Fernández, E., Roca-Riu, M., Speranza, M.G., 2018. The shared customer collaboration vehicle routing problem. European Journal of Operational Research 265, 1078-1093.

Fochler, V., 2005. Die GüterBim - ein erfolgreiches Projekt und seine Umsetzung. https://www . staedtebund .gv . at/gemeindezeitung/oegz-beitraege/oegz-beitraege-details/artikel/diegueterbim-ein-erfolgreiches-projekt-und-seine-umsetzung.html. Accessed May 2017.

Földes, D., Csiszár, C., 2017. Model of information system for combined ride-sourcing service, in: Smart City Symposium Prague (SCSP), 2017, IEEE. pp. 1-6.

Frisk, M., Göthe-Lundgren, M., Jörnsten, K., Rönnqvist, M., 2010. Cost allocation in collaborative forest transportation. European Journal of Operational Research 205, 448-458.

Furuhata, M., Dessouky, M., Ordóñez, F., Brunet, M.E., Wang, X., Koenig, S., 2013. Ridesharing: The state-of-the-art and future directions. Transportation Research Part B: Methodological 57, 28-46. doi:10. $1016 /$ j.trb.2013.08.012.

Gansterer, M., Hartl, R.F., 2016. Request evaluation strategies for carriers in auction-based collaborations. OR Spectrum 38, 3-23. doi:10.1007/s00291-015-0411-1.

Gansterer, M., Hartl, R.F., 2017. Collaborative vehicle routing: a survey. European Journal of Operational Research 268, 1-12.

Ghilas, V., Demir, E., Van Woensel, T., 2013. Integrating passenger and freight transportation: Model formulation and insights, in: Beta Working Papers WP 441. Technische Universiteit Eindhoven.

Ghilas, V., Emrah, D., Van Woensel, T., 2016a. An adaptive large neighborhood search heuristic for the pickup and delivery problem with time windows and scheduled lines. Computers \& Operations Research $72,12-30$

Ghilas, V., Emrah, D., Van Woensel, T.,2016b. The pickup and delivery problem with time windows and scheduled lines. INFOR: Information Systems and Operational Research 54, 147 - 167.

Ghilas, V., Emrah, D., Van Woensel, T., 2016c. A scenario-based planning for the pickup and delivery problem with time windows, scheduled lines and stochastic demands. Transportation Research Part B: Methodological 91, $34-51$.

Gonzalez-Feliu, J., 2014. Costs and benefits of railway urban logistics: a prospective social cost benefit analysis. Technical Report. HAL.

Gonzalez-Feliu, J., Morana, J., 2014. Assessing urban logistics pooling sustainability via a hierarchic dashboard from a group decision perspective, in: Sustainable Logistics. Emerald Group Publishing Limited, pp. 113-135.

Gonzalez-Feliu, J., Morana, J., Grau, J.M.S., Ma, T.Y., 2013. Design and scenario assessment for collaborative logistics and freight transport systems. International Journal of Transport Economics 40, $207-240$.

Grangier, P., Gendreau, M., Lehuédé, F., Rousseau, L.M., 2016. An adaptive large neighborhood search for the two-echelon multiple-trip vehicle routing problem with satellite synchronization. European Journal of Operational Research 254, 80-91.

Guajardo, M., Jörnsten, K., Rönnqvist, M., 2016. Constructive and blocking power in collaborative transportation. OR Spectrum 38, 25-50. doi:10.1007/s00291-015-0413-z.

Guajardo, M., Rönnqvist, M., 2015. Operations research models for coalition structure in collaborative logistics. European Journal of Operational Research 240, 147-159. doi:10.1016/j.ejor.2014.06.015.

Guajardo, M., Rönnqvist, M., 2016. A review on cost allocation methods in collaborative transportation. International Transactions in Operational Research 23, 371-392. doi:10.1111/itor.12205.

Guihaire, V., Hao, J.K., 2008. Transit network design and scheduling: A global review. Transportation Research Part A: Policy and Practice 42, 1251 - 1273. URL: http://www.sciencedirect.com/science/ 
article/pii/S0965856408000888, doi:http://dx.doi.org/10.1016/j.tra.2008.03.011.

Haffner, F., 2013. Erfolgsgeschichte Cargo-Tram. Höngger Online Accessed May 2017.

Hamari, J., Sjöklint, M., Ukkonen, A., 2015. The sharing economy: Why people participate in collaborative consumption. Journal of the Association for Information Science and Technology 67.

Hammervoll, T., Bø, E., 2010. Shipper-carrier integration: overcoming the transparency problem through trust and collaboration. European Journal of Marketing 44, 1121-1139.

Hezarkhani, B., Slikker, M., Van Woensel, T., 2016. A competitive solution for cooperative truckload delivery. OR Spectrum 38, 51-80. doi:10.1007/s00291-015-0394-y.

Hingley, M., Lindgreen, A., Grant, D.B., Kane, C., 2011. Using fourth-party logistics management to improve horizontal collaboration among grocery retailers. Supply Chain Management: An International Journal 16, 316-327.

Ilie-Zudor, E., Ekárt, A., Kemeny, Z., Buckingham, C., Welch, P., Monostori, L., 2015. Advanced predictiveanalysis-based decision support for collaborative logistics networks. Supply Chain Management: An International Journal 20, 369-388. URL: http://www.emeraldinsight.com/doi/10.1108/SCM-102014-0323.

Iwan, S., Kijewska, K., Lemke, J., 2016. Analysis of parcel lockers efficiency as the last mile delivery solution-the results of the research in Poland. Transportation Research Procedia 12, 644-655.

James, G.G.I., 2001. Method to schedule a vehicle in real-time to transport freight and passengers. U.S. Classification 701/410, 701/26, 340/991, 340/994, 701/465, 701/533; International Classification G06Q10/08, G06Q10/04, G01C21/34, G08G1/123; Cooperative Classification G06Q10/047, G01C21/343, G08G1/202, G06Q10/08; European Classification G06Q10/08, G01C21/34A3, G08G1/20A, G06Q10/047.

Jespersen-Groth, J., Potthoff, D., Clausen, J., Huisman, D., Kroon, L., Maróti, G., Nielsen, M.N., 2009. Disruption Management in Passenger Railway Transportation. Springer Berlin Heidelberg. pp. 399-421. URL: http://dx.doi.org/10.1007/978-3-642-05465-5_18, doi:10.1007/978-3-642-05465-5_18.

Kimms, A., Kozeletskyi, I., 2016a. Core-based cost allocatiøn in the cooperative traveling salesman problem. European Journal of Operational Research 248, 910-916.

Kimms, A., Kozeletskyi, I., 2016b. Shapley value-based cost allocation in the cooperative traveling salesman problem under rolling horizon planning. EURO Journal on Transportation and Logistics 5, 371-392.

Kin, B., Verlinde, S., Macharis, C., 2017. Sustainable urban freight transport in megacities in emerging markets. Sustainable Cities and Society 32, 31-41. URL: http://dx.doi.org/10.1016/j .scs. 2017. 03.011.

König, A., Spinler, S., 2016. The effect of logistics outsourcing on the supply chain vulnerability of shippers. The International Journal of Logistics Management 27, 122-141.

Köster, F., Ulmer, M.W., Mattfeld, D.C., 2015. Cooperative traffic control management for city logistic routing. Transportation Research Procedia 10, 673-682. doi:10.1016/j.trpro.2015.09.021.

Krajewska, M.A., Kopfer, H., Laporte, G., Ropke, S., Zaccour, G., 2008. Horizontal cooperation among freight carriers: Request allocation and profit sharing. Journal of the Operational Research Society 59, 1483-1491. doi:10.1057/palgrave.jors. 2602489.

Le Pira, M., Marcucci, E., Gatta, V., Ignaccolo, M., Inturri, G., Pluchino, A., 2017. Towards a decisionsupport procedure to foster stakeholder involvement and acceptability of urban freight transport policies. European Transport Research Review 9, 54.

Li, B., Krushinsky, D., Reijers, H.A., Van Woensel, T., 2014. The share-a-ride problem: People and parcels sharing taxis. European Journal of Operational Research 238, 31-40. doi:10.1016/j . ejor .2014.03.003.

Li, B., Krushinsky, D., Van Woensel, T., Reijers, H.A., 2016a. An adaptive large neighborhood search heuristic for the share-a-ride problem. Computers \& Operations Research 66, 170-180. doi:10.1016/j . cor. 2015.08.008.

Li, B., Krushinsky, D., Van Woensel, T., Reijers, H.A., 2016b. The share-a-ride problem with stochastic travel times and stochastic delivery locations. Transportation Research Part C: Emerging Technologies 67, 95-108. doi:10.1016/j.trc.2016.01.014.

Li, J., Cai, X., Zeng, Y., 2016c. Cost allocation for less-than-truckload collaboration among perishable 
product retailers. OR Spectrum 38, 81-117. doi:10.1007/s00291-015-0424-9.

Linares, M.P., Montero, L., Barceló, J., Carmona, C., 2016. A simulation framework for real-time assessment of dynamic ride sharing demand responsive transportation models, in: Proceedings of the 2016 Winter Simulation Conference, IEEE Press. pp. 2216-2227.

Lozano, S., Moreno, P., Adenso-Díaz, B., Algaba, E., 2013. Cooperative game theory approach to allocating benefits of horizontal cooperation. European Journal of Operational Research 229, 444-452.

Macharis, C., Kin, B., 2017. The 4 A's of sustainable city distribution: Innovative solutions and challenges ahead. International Journal of Sustainable Transportation 11, 59-71. doi:10.1080/15568318.2016. 1196404.

Manier, H., Manier, M.A., Al Chami, Z., 2016. Shippers' collaboration in city logistics. IFAC-PapersOnLine 49, 1880-1885.

Marinov, M., Giubilei, F., Gerhardt, M., Özkan, T., Stergiou, E., Papadopol, M., Cabecinha, L., 2013. Urban freight movement by rail. Journal of Transport Literature 7, 87-116.

Mason, R., Lalwani, C., Boughton, R., 2007. Combining vertical and horizontal collaboration for transport optimisation. Supply Chain Management: An International Journal 12, 187-199.

Masson, R., Trentini, A., Lehuédé, F., Malhéné, N., Péton, O., Tlahig, H., 2017, Optimization of a city logistics transportation system with mixed passengers and goods. EURO Journal on Transportation and Logistics 6, 81-109. URL: http://dx.doi.org/10.1007/s13676-015-0085-5, doi:10.1007/s13676015-0085-5.

Matthaei, R.F., 2017. Straßenbahnen in Hamburg: Straßenbahn und Post. URL: http://fredriks.de/ hvv1/strabpostverkehr.php. accessed May 2017.

McFarlane, D., Giannikas, V., Lu, W., 2016. Intelligent logistics: Involving the customer. Computers in Industry $81,105-115$.

Mingardo, G., 2008. Cities and innovative urban transport policies. Innovation 10, 269-281.

Moglestue, A., 2013. Cargotram: Zürich's refuse takes to the tram! Tramways \& Urban Transit , $298-299$.

Montoya-Torres, J.R., Muñoz-Villamizar, A., Vega-Mejía, C.A., 2016. On the impact of collaborative strategies for goods delivery in city logistics. Production Planning \& Control 27, 443-455.

Morana, J., Gonzalez-Feliu, J., Semet, F., 2014. Urban consolidation and logistics pooling, in: Sustainable urban logistics: Concepts, methods and information systems. Springer, pp. 187-210.

Morganti, E., Dablanc, L., Fortin, F., 2014a. Final deliveries for online shopping: The deployment of pickup point networks in urban and suburban areas. Research in Transportation Business \& Management 11, 23-31. doi:10.1016/j.rtbm.2014.03.002.

Morganti, E., Seidel, S., Blanquart, C., Dablanc, L., Lenz, B., 2014b. The impact of e-commerce on final deliveries: Alternative parcel delivery services in France and Germany. Transportation Research Procedia 4, 178-190. doi:10.1016/j. trpro.2014.11.014.

Motraghi, A., 2013. Rail research projects: Case studies. Research in transportation economics 41, 76-83.

Motraghi, A., Marinov, M.V., 2012. Analysis of urban freight by rail using event based simulation. Simulation modelling practice and theory $25,73-89$.

Muñoz-Villamizar, A., Montoya-Torres, J.R., Faulin, J., 2017. Impact of the use of electric vehicles in collaborative urban transport networks: A case study. Transportation Research Part D: Transport and Environment 50, 40-54. doi:10.1016/j.trd.2016.10.018.

Nagy, G., Salhi, S., 2007. Location-routing: Issues, models and methods. European Journal of Operational Research 177, 649 - 672. URL: http://www.sciencedirect.com/science/article/pii/ S0377221706002670, doi:http://dx.doi.org/10.1016/j.ejor.2006.04.004.

Nguyen, N.Q., Nghiem, N.V.D., Do, P.T., Le, K.T., Nguyen, M.S., Mukai, N., 2015. People and parcels sharing a taxi for Tokyo city, in: Proceedings of the Sixth International Symposium on Information and Communication Technology, ACM. pp. 90-97.

Nguyen, P.K., Crainic, T.G., Toulouse, M., 2013. A tabu search for time-dependent multi-zone multi-trip vehicle routing problem with time windows. European Journal of Operational Research 231, 43-56.

Okdinawati, L., Simatupang, T.M., Sunitiyoso, Y., 2015. Modelling collaborative transportation management: Current state and opportunities for future research. Journal of Operations and Supply Chain 
Management 8, 96. URL: http://bibliotecadigital.fgv.br/ojs/index.php/joscm/article/view/ 58064.

Ouhader, H., El Kyal, M., 2017. Combining facility location and routing decisions in sustainable urban freight distribution under horizontal collaboration: How can shippers be benefited? Mathematical Problems in Engineering 2017.

Özener, O.Ö., Ergun, Ö., Savelsbergh, M., 2011. Lane-exchange mechanisms for truckload carrier collaboration. Transportation Science 45, 1-17. doi:10.1287/trsc.1100.0327.

Palhazi Cuervo, D., Vanovermeire, C., Sörensen, K., 2016. Determining collaborative profits in coalitions formed by two partners with varying characteristics. Transportation Research Part C: Emerging Technologies 70, 171-184. doi:10.1016/j.trc.2015.12.011.

Paloheimo, H., Lettenmeier, M., Waris, H., 2016. Transport reduction by crowdsourced deliveries-a library case in Finland. Journal of Cleaner Production 132, 240-251.

Pellegrini, P., Rodriguez, J., 2013. Single European sky and single European railway area: A system level analysis of air and rail transportation. Transportation Research Part A: Policy and Practice 57, 64-86.

Perboli, G., Tadei, R., Vigo, D., 2011. The two-echelon capacitated vehicle routing problem: Models and math-based heuristics. Transportation Science 45, 364-380.

Pomponi, F., Fratocchi, L., Tafuri, S.R., Palumbo, M., Pomponi, F., Fratocchi, L., Tafuri, S.R., Palumbo, M., 2013. Horizontal collaboration in logistics: a comprehensive framework. Research in Logistics \& Production 3, 243-254.

Punel, A., Stathopoulos, A., 2017. Modeling the acceptability of crowdsourced goods deliveries: Role of context and experience effects. Transportation Research Part E: Logistics and Transportation Review 105, 18-38.

Quak, H.J.H., de Koster, M.R.B.M., 2009. Delivering goods in urban areas: How to deal with urban policy restrictions and the environment. Transportation Science 43,211-227. doi:10.1287/trsc.1080.0235.

Rai, H.B., Verlinde, S., Merckx, J., Macharis, C., 2017. Crowdlogistics: an opportunity for more sustainable urban freight transport? European Transport Research Review 9, 39.

Regué, R., Bristow, A.L., 2012. Exploring scenarios for the introduction of freight trams in Barcelona, in: Proceedings of 91st Annual Meeting of Transportation Research Board (TRB), pp. 1-15.

Regué, R., Bristow, A.L., 2013. Appraising freight tram schemes: A case study of Barcelona. European Journal of Transport and Infrastructure Research 13, 56-78.

Repolho, H.M., Church, R.L., Antunes, A.P., 2016. Optimizing station location and fleet composition for a high-speed rail line. Transportation Research Part E: Logistics and Transportation Review 93, 437 - 452. URL: http://www.sciencedirect.com/science/article/pii/S1366554516304185, doi:http: //dx.doi.org/10.1016/j.tre.2016.06.006.

Reyes, D., Savelsbergh, M., Toriello, A., 2017. Vehicle routing with roaming delivery locations. Transportation Research Part C: Emerging Technologies 80, 71-91.

Robinson, S.E., 1995. A Geographical Analysis of the Role of Unconventional Public Transport in Selected Rural Areas of Scotland. Master thesis. Durham University.

Roma, P., Perrone, G., 2016. Cooperation among competitors: A comparison of cost-sharing mechanisms. International Journal of Production Economics 180, 172-182. URL: http://dx.doi.org/10.1016/j . ijpe.2016.08.002.

Ronald, N., Yang, J., Thompson, R.G., 2016. Exploring co-modality using on-demand transport systems. Transportation Research Procedia 12, 203-212. doi:10.1016/j.trpro.2016.02.059.

Rose, W.J., Bell, J.E., Autry, C.W., Cherry, C.R., 2017. Urban logistics : Establishing key concepts and building a conceptual framework for future research. Transportation Journal 56, 357-394.

Rougès, J.F., Montreuil, B., 2014. Crowdsourcing delivery: New interconnected business models to reinvent delivery, in: 1 St International Physical Internet Conference, pp. 28-30.

Saeedi, H., Wiegmans, B., Behdani, B., Zuidwijk, R., 2017. Analyzing competition in intermodal freight transport networks: The market implication of business consolidation strategies. Research in Transportation Business and Management 23, 12-20.

Savelsbergh, M., Van Woensel, T., 2016. 50th anniversary invited article - city logistics: Challenges and 
opportunities. Transportation Science 50, 579-590.

Schmidt, G., Wilhelm, W.E., 2000. Strategic, tactical and operational decisions in multi-national logistics networks: a review and discussion of modelling issues. International Journal of Production Research 38, $1501-1523$.

Schmoltzi, C., Wallenburg, C.M., 2011. Horizontal cooperations between logistics service providers: Motives, structure, performance. International Journal of Physical Distribution \& Logistics Management 41, 552575. doi:10.1108/09600031111147817.

Schmoltzi, C., Wallenburg, C.M., 2012. Operational governance in horizontal cooperations of logistics service providers: performance effects and the moderating role of cooperation complexity. Journal of Supply Chain Management 48, 53-74.

Seok, H., Nof, S.Y., 2014. Dynamic coalition reformation for adaptive demand and capacity sharing. International Journal of Production Economics 147, 136-146. URL: http://dx.doi.org/10.1016/j.ijpe. 2013.09.003.

Shen, J., Qiu, F., Li, W., Feng, P., 2015. A new urban logistics transport system based on a public transit service, in: CICTP 2015, pp. 650-661. URL: http://ascelibrary.org/doi/abs/10.1061/ 9780784479292.060, doi:10.1061/9780784479292.060.

Simmer, L., Pfoser, S., Grabner, M., Schauer, O., Putz, L.M., 2017. From horizontal collaboration to the physical internet - a case study from Austria. International Journal of Transport Development and Integration 1, 129-136.

Slabinac, M., 2016. Innovative solutions for a "last-mile" delivery-a European experience, in: Business Logistics in Modern Management, pp. 111-129.

Sternberg, H., Norrman, A., 2017. The physical internet-review, analysis and future research agenda. International Journal of Physical Distribution \& Logistics Management 47, 736-762.

Stocker, A., Shaheen, S., 2017. Shared automated vehicles: Review of business models, in: International Transport Forum.

Taniguchi, E., Van Der Heijden, R.E., 2000. An evaluation methodology for city logistics. Transport Reviews 20, 65-90.

Tavasszy, L.A., Ruijgrok, K., Davydenko, I., 2012. Incorporating logistics in freight transport demand models: State-of-the-art and research opportunities. Transport Reviews 32, 203-219.

Thompson, R.G., Hassall, K.P., 2012, A collaborative urban distribution network. Procedia - Social and Behavioral Sciences 39, 230 - 240. URL: http://www.sciencedirect.com/science/article/pii/ S187704281200571X, doi:http://dx.doi.org/10.1016/j.sbspro.2012.03.104.

Uber Technologies, Inc., 2017. Uberrush. https://rush.uber.com/how-it-works. Accessed May 2017.

Vanovermeire, C., Sörensen, K., 2014. Integration of the cost allocation in the optimization of collaborative bundling. Transportation Research Part E: Logistics and Transportation Review 72, 125-143.

Vanovermeire, C., Sörensen, K., Van Breedam, A., Vannieuwenhuyse, B., Verstrepen, S., 2014. Horizontal logistics collaboration: Decreasing costs through flexibility and an adequate cost allocation strategy. International Journal of Logistics Research and Applications 17, 339-355. URL: http://dx.doi.org/ $10.1080 / 13675567.2013 .865719$.

Verdonck, L., Beullens, P., Caris, A., Ramaekers, K., Janssens, G.K., 2016. Analysis of collaborative savings and cost allocation techniques for the cooperative carrier facility location problem. Journal of the Operational Research Society 67, 853-871.

Verstrepen, S., Cools, M., Cruijssen, F., Dullaert, W., 2009. A dynamic framework for managing horizontal cooperation in logistics. International Journal of Logistics Systems and Management 5, 228-248.

Wang, X., Kopfer, H., 2014. Collaborative transportation planning of less-than-truckload freight: A routebased request exchange mechanism. OR Spectrum 36, 357-380. doi:10.1007/s00291-013-0331-x.

Wang, X., Kopfer, H., Gendreau, M., 2014. Operational transportation planning of freight forwarding companies in horizontal coalitions. European Journal of Operational Research 237, 1133-1141. doi:10. $1016 /$ j.ejor.2014.02.056.

Wäscher, G., Haußner, H., Schumann, H., 2007. An improved typology of cutting and packing problems. European Journal of Operational Research 183, 1109-1130. 
WHO, 2010. Hidden Cities: unmasking and overcoming health inequities in urban settings. Technical Report. World Health Organization.

Woodburn, A., Browne, M., Allen, J., 2015. Urban railway hub freight expansion feasability study: final report to Cross River Partnership. Technical Report. University of Westminster.

Wu, H., Shao, D., Ng, W.S., 2015. Locating self-collection points for last-mile logistics using public transport data, in: Pacific-Asia Conference on Knowledge Discovery and Data Mining, Springer. pp. 498-510.

Ziegler, M., 2007. "güterbim" rollt aufs Abstellgleis. Wiener Zeitung URL: http://www . wienerzeitung . at/ nachrichten/wien/stadtleben/269144_Gueterbim-rollt-aufs-Abstellgleis.html. accessed May 2017.

Zych, M., 2014. Identification of potential implementation of the cargo tram in Warsaw: A first oyerview. Procedia - Social and Behavioral Sciences 151, 360-369. doi:10.1016/j . sbspro.2014.10.034. 